\title{
Crowd disasters as systemic failures: analysis of the Love Parade disaster
}

Dirk Helbing ${ }^{1,2^{*}}$ and Pratik Mukerji ${ }^{1}$

\author{
${ }^{*}$ Correspondence: \\ dhelbing@ethz.ch \\ ${ }^{1}$ Risk Center, ETH Zurich, Swiss \\ Federal Institute of Technology, \\ Scheuchzerstrasse 7, 8092 Zurich, \\ Switzerland \\ 2Santa Fe Institute, 1399 Hyde Park \\ Road, Santa Fe, NM 87501, USA
}

\begin{abstract}
Each year, crowd disasters happen in different areas of the world. How and why do such disasters happen? Are the fatalities caused by relentless behavior of people or a psychological state of panic that makes the crowd 'go mad'? Or are they a tragic consequence of a breakdown of coordination? These and other questions are addressed, based on a qualitative analysis of publicly available videos and materials, which document the planning and organization of the Love Parade in Duisburg, Germany, and the crowd disaster on July 24, 2010. Our analysis reveals a number of misunderstandings that have widely spread. We also provide a new perspective on concepts such as 'intentional pushing,' 'mass panic', 'stampede', and 'crowd crushes'. The focus of our analysis is on the contributing causal factors and their mutual interdependencies, not on legal issues or the judgment of personal or institutional responsibilities. Video recordings show that people stumbled and piled up due to a 'domino effect', resulting from a phenomenon called 'crowd turbulence' or 'crowd quake.' Crowd quakes are a typical reason for crowd disasters, to be distinguished from crowd disasters resulting from 'mass panic' or 'crowd crushes'. In Duisburg, crowd turbulence was the consequence of amplifying feedback and cascading effects, which are typical for systemic instabilities. Accordingly, things can go terribly wrong in spite of no bad intentions from anyone. Comparing the incident in Duisburg with others, we give recommendations to help prevent future crowd disasters. In particular, we introduce a new scale to assess the criticality of conditions in the crowd. This may allow preventative measures to be taken earlier on. Furthermore, we discuss the merits and limitations of citizen science for public investigation, considering that today, almost every event is recorded and reflected in the World Wide Web.
\end{abstract}

Keywords: crowd disaster; causality network; crowd control; domino effect; crowd quake; evacuation; cascading effect; systemic risk; instability

\section{Introduction}

Crowd disasters are known since at least the Roman Empire. As a consequence, building codes for stadia were developed. The Coliseum in Rome, Italy, which is considered to be one of the seven world wonders, is probably the best known example of Roman building experience. While it could take up between 50,000 and 73,000 visitors, it had more than 60 numbered entrances, and visitors exited through the same gate through which they had entered. In fact, exits were located side by side, around the entire circumference of the Coliseum. As a consequence, the Coliseum could be evacuated within just about 5 minutes, an efficiency that is not even reached by modern stadia due to their smaller number of exits.

(c) 2012 Helbing and Mukerji; licensee Springer. This is an Open Access article distributed under the terms of the Creative Commons Attribution License (http://creativecommons.org/licenses/by/2.0), which permits unrestricted use, distribution, and reproduction in any medium, provided the original work is properly cited. 
Building codes and regulations for mass events have also been written and updated after recent crowd disasters, such as the ones in Bradford (1985) or Hillsborough, Sheffield (1989) [1-5]. ${ }^{1,2,3,4}$ Today's knowledge about the dynamics of crowds is considerable and summarized in Refs. [6-11]. Furthermore, a lot of experience in organizing safer mass events has recently been gained from the organization of religious pilgrimage [12-16]. In recent years, there is also a quickly growing body of literature on evacuation experiments $[10,11,17-25]$ and pedestrian simulations [8, 23, 26-37], and various related commercial software products are now available. Thus, how was it possible that 21 people died and more than 500 were injured during the Love Parade on July 24, 2010?

A crucial point for the safety of mass events is that they are (or at least should be) organized in a way that is robust against many kinds of disturbances (such as weather conditions, human errors, etc.). This is why the organization of a mass event includes the elaboration of contingency plans. Why then can crowd disasters still happen?

This paper will reveal that the Love Parade disaster was not the result of a single mistake. We will rather show that the Love Parade disaster resulted from the interaction of several contributing factors. It is probably the first time that a detailed analysis can be performed with publicly available documents: not just investigation reports by public authorities ${ }^{6,7}$ and the media, but also maps from Google Earth ${ }^{8}$ and 360 degree photographs, ${ }^{9}$ videos accessible through YouTube, ${ }^{10}$ documents released by Wikipedia ${ }^{11,12,13}$ and Wikileaks, ${ }^{14}$ and other sources. In some sense, this opens up a new age of public investigation. However, to avoid misunderstandings, we would like to underline that our analysis focuses on the course of events and causal interdependencies among them, while they do not draw any conclusions regarding legal issues or personal or institutional responsibilities, which must be judged by other experts. ${ }^{15}$

The remainder of this paper is structured as follows: Section 2 provides an overview of the situation before and during the Love Parade disaster. This includes a historical background, a description of the festival area (including in- and outflows), and a timeline reconstructed from many video recordings. Section 3 will analyze various factors contributing to the disaster, while Section 4 will focus on causal interdependencies and interaction effects. Section 5 discusses our findings and Section 6 concludes with lessons learned for the organization of future mass events. The novelty of this paper is four-fold: it concerns (1) the structured analysis of large amounts of publicly available video recordings of a disaster, (2) the interpretation of the disaster as a systemic failure (where the interaction of various factors created a systemic instability, causing an overall loss of control), (3) a revision of common views about crowd disasters, and (4) the introduction of a scale reflecting the criticality of crowd conditions (and proposed counter-measures).

\section{Overview of the situation}

The following section will try to give a short overview of the situation during the Love Parade in Duisburg and the planning beforehand. A large number of documents are now publicly available (see collection of links). ${ }^{16}$ This includes the planning documents, ${ }^{14}$ the event $\log$ of the regulatory authority of the city of Duisburg, ${ }^{17}$ and the evacuation analysis. ${ }^{18}$ Publicly accessible materials and eye witness reports now amount to several hundred pages $^{19}$ and more than 500 video recordings. ${ }^{20}$ This useful collection of materials is the result of the efforts of many volunteers. It is certainly not possible (but also not the purpose) of this article to give a complete representation of materials. We will rather focus 
on the most relevant details in order to avoid a distraction of the reader from the main factors that have contributed to the disaster.

The interested reader is invited to gain a more complete picture himself or herself, based on the media reports provided ${ }^{21,22,23}$ and of several TV channels. ${ }^{24,25,26}$ The view of the organizer is presented in a video documentation. ${ }^{27}$ Further video documentations are available from private persons. ${ }^{28,29,30,31}$ An interpretation of the events, overlaid to a satellite picture, can be found on YouTube. ${ }^{32}$

In order to make an independent assessment possible, our own analysis will largely refer to authentic materials that are publicly accessible. Videos of a subset of surveillance cameras are available until 16:40.33

Timelines can be found in the endnotes. ${ }^{6,17,34}$ Complementary to this article, we provide a time-ordered and geo-located collection of videos from visitors of the Love Parade. ${ }^{35}$ A YouTube channel with videos of the Love Parade exists as well. ${ }^{8}$ The collection ${ }^{20}$ contains further videos. Many of these videos have been synchronized, ${ }^{36,37}$ and some of them have been cut together in the form of multi-view videos documenting the course of events. ${ }^{38}$ A set of highly relevant private videos around the time of the disaster can be found on YouTube. $37,39,40,41,42,43,44,45,46,47,48$

Note that, when referring to secondary sources (such as public media reports), we will sometimes use wordings such as 'apparently' or 'seems to', in order to indicate that access to primary sources would be desirable for an in-depth analysis.

\subsection{History of the Love Parade}

The Love Parade is a popular electronic dance music festival in Germany that was first organized in Berlin in 1989, and annually repeated in the same city until 2003. The events in 2004 and 2005 had to be cancelled because of funding problems and a coordinated opposition of political parties (e.g. related to the waste resulting from the event). ${ }^{11}$ In 2006 , the parade made a comeback with the support of a fitness studio. The Love Parade in summer 2007 was again planned for Berlin, but the event was cancelled, since the Senate of Berlin did not issue the necessary permits on time. After negotiations with several German cities, it was then decided to move the Love Parade to the Ruhr Area, an agglomerate of major German cities, in the next years. The first of these events took place in Essen on August 25, 2007, with 1.2 million visitors. In July 2008, it was organized in Dortmund. The 2009 event, planned for Bochum, was cancelled due to security concerns, particularly as a critical situation had apparently occurred the year before. ${ }^{12}$ The last Love Parade took place on July 24, 2010, in Duisburg, where 21 people died and more than 500 were injured in a crowd disaster. The chain of events underlying this disaster will be analyzed in the following sections.

\subsection{Description of the festival area}

The festival area of the Love Parade in 2010 was approximately 100,000 square meters large ${ }^{21}$ and located in the area of a previous freight station of the city of Duisburg. For a 360 degree view of the festival area and its surroundings see the endnotes. ${ }^{9}$ In contrast to the open area concept of the Love Parade in Berlin (see the picture in the endnotes), ${ }^{49}$ the annual Carnival in Cologne, and the 20th World Youth Day gathering with the Catholic Pope in 2005 in Cologne-Marienfeld, Germany, ${ }^{50}$ the festival area was constrained by railway tracks on the East and by a freeway on the West. In response to concerns from 
the regulatory authority that the area would be too small for the expected number of up to 1.4 million expected visitors, ${ }^{21}$ the city of Duisburg combined its late approval of the event with the condition to restrict the number of concurrent visitors to 250,000.

To overcome security issues seen by the regulatory authority (there was some discussion to cancel the event overall), the organizer of the Love Parade decided to fence the whole festival area. This moved the responsibility to the building regulatory agency ${ }^{21}$ and required the event to satisfy the 'Versammlungsstättenverordnung, ${ }^{4}$ which is the German safety regulation for the organization of mass events. However, there were still concerns that the standard safety requirements would not be met. It is conceivable that these concerns were not fully considered due to a desire to approve the event, ${ }^{51}$ particularly as Duisburg was nominated as Germany's 'cultural capital' of the year, and the opinion prevailed that the Love Parade would make the cultural program and the city more attractive. ${ }^{21}$ To overcome the concerns, an expert opinion was requested from a prominent crowd researcher. The report argued that the festival area could be sufficiently well evacuated in an emergency situation. ${ }^{18}$ However, the study did not analyze normal entry and exit conditions in detail.

Figure 1 gives an overview of the festival area. It shows that the festival area could be entered only via a tunnel, 'Karl-Lehr-Straße', which also served as the only exit from the area. In the middle of that tunnel, there is the main ramp that leads to the festival area. The tunnel and the ramp together determine an inverse T-shaped geometry of in- and outflows. A side ramp in the West ('Am Güterbahnhof') was assigned as an additional exit ramp, ${ }^{6}$ but basically not used. The smallest overall diameter of the tunnels in the East and in the West was about 20 meters. $^{13}$ The ramp itself was 26 meters wide and 130 meters long. ${ }^{21}$ Based on the maximum flow value of 1.225 persons per meter per second [38], this would imply a hypothetical maximum flow of 114,660 persons per hour and a density of 1.75 persons per square meter, if the entire ramp width was usable. However, the actual capacity was significantly lower than this due to the following factors (see also Sec. 2.3):

1 The maximum possible flow is inconvenient and potentially unsafe, and therefore not suited as a basis for planning [6,39-41].

2 Counterflows are expected to reduce the capacity by 6-14\% [38], resulting in a maximum hypothetical flow of 98,608 persons per hour.

3 The 90 degree turn to and from the tunnels is expected to reduce the capacity as well.

4 Walking in groups reduces the capacity further [42].

5 Alcohol and drugs are expected to have a negative impact on capacity as well.

6 A considerable amount of capacity must have been lost due to fences, ${ }^{52}$ a food stand, ${ }^{53}$ and vehicles on the side of the ramp. ${ }^{54}$

The flow model of the organizer assumed numbers in Table $1 .^{55}$

According to Table 1, between 17:00 and 18:00 the organizers expected an inflow of 90,000 and an outflow of 55,000 people, which could not have been handled by the wide ramp without the use of suitable crowd control. Problems had to be expected already for much smaller flow rates, as there were vehicles and a food stand as well as fences on the ramp, which must have reduced its capacity considerably. This risk factor certainly had to be carefully considered by the crowd management concept. In fact, the side ramp (see Figure 1) was attributed as an additional exit ramp, and the organizational concept foresaw the possibility to reduce the visitor flows through 'isolating devices' (access control 


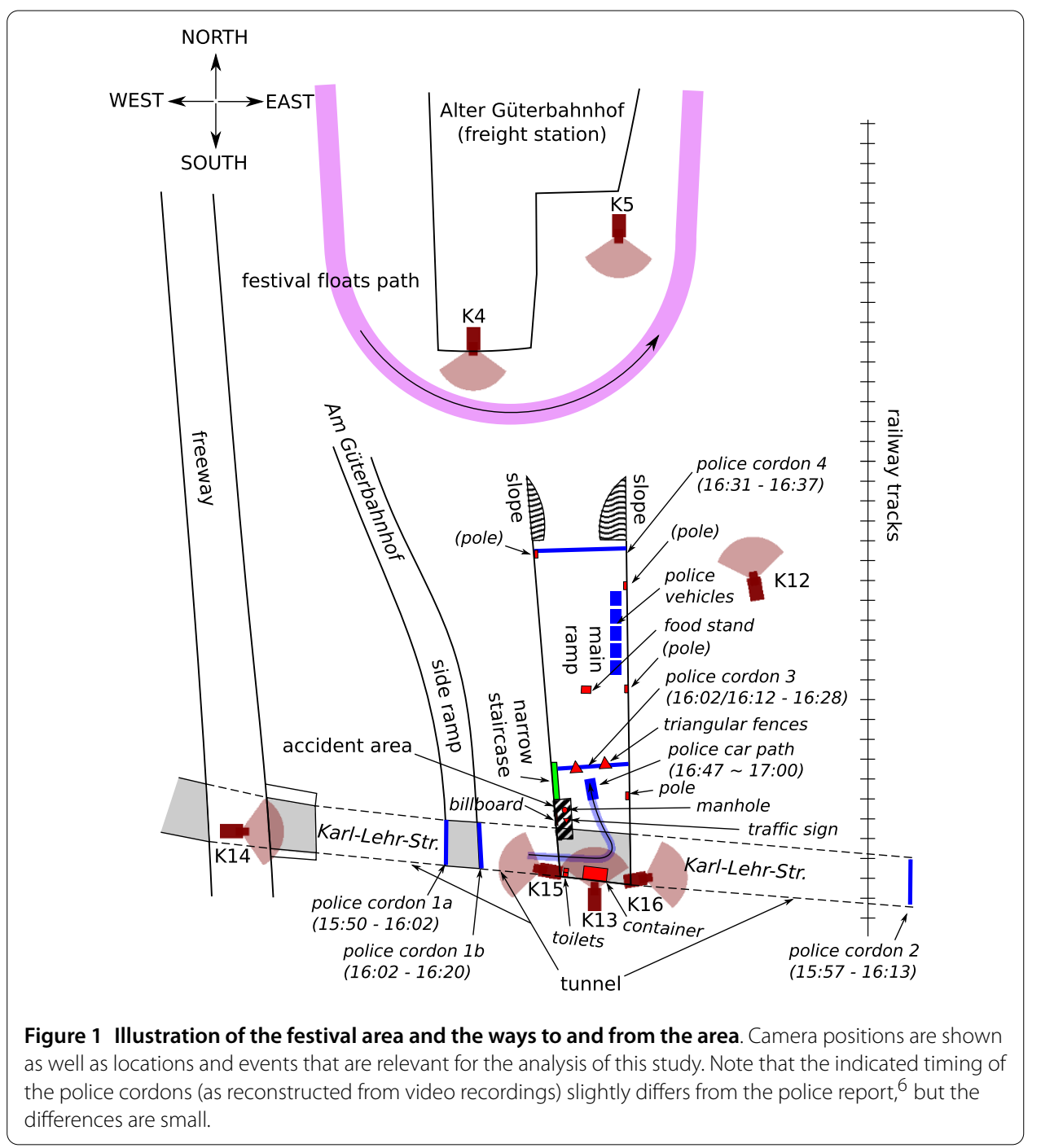

points), which were located in front of the tunnel entrances. ${ }^{56}$ Despite this, access control was given up intermittently because of the large pressure from incoming visitors (see the endnote ${ }^{6}$ and Tables 2 to 4). The festival area itself was apparently not overcrowded (see caption of Table 1 and aerial photographs). ${ }^{57,58}$ So, why and how did the crowd disaster happen in the inverse T-section formed by the tunnel and the ramp, even though the visitor flows were apparently smaller than expected (see Table 1) and a more than 3,000 people strong police force was on duty? To address this question, we will first present an expert opinion on the crowd disaster. Then, we will summarize the course of events, and analyze the contributing factors in more detail.

\subsection{Expert report by Prof. Dr. G. Keith Still}

An expert report dated December 9, 2011, which became public in February 2012, ${ }^{59}$ analyzes the implications of the flow model presented in Table 1. In the following, we summarize the essence of this report in our own words: 
Table 1 Expected inflows and outflows estimated by the organizers (see endnote ${ }^{55}$ for more details)

\begin{tabular}{lcc}
\hline Time & Expected inflow/h & Expected outflow/h \\
\hline 14:00-15:00 & 55,000 & 10,000 \\
15:00-16:00 & 55,000 & 50,000 \\
16:00-17:00 & 55,000 & 45,000 \\
17:00-18:00 & 90,000 & 55,000 \\
\hline
\end{tabular}

Based on these values, the maximum number of visitors on the festival area was expected to be 235,000 (while a capacity of 250,000 was approved and more than 1 million visitors were expected, according to announcements before and during the event). ${ }^{60}$ Estimates based on surveillance videos of camera 13 suggest that the actual flows were considerably below the values in the above table. According to the endnote, ${ }^{61}$ the inflow in the time period between 14:00 and 15:00 varied between 280 and 600 persons per minute and the outflow between 6 and 80 persons per minute. Between 15:00 and 15:40, it varied between 450 and 750 persons per minute and the outflow between 40 and 250 persons per minute. This is $30-50 \%$ below expectations of the organizer of the Love Parade and implies a maximum number of visitors on the festival area of about 175,000 .

1 Safe crowd conditions can be usually assumed for densities up to 2-3 persons per meter and minute and a maximum acceptable flow of 82 persons per meter and minute (which is considerably below the maximum possible flow) [41].

2 All areas, in which higher crowd densities may occur or where many people may accumulate, must be analyzed for risks.

3 The safety concept must list those risks and also, who is responsible to handle them. The organizational structure (in particular, who takes what kinds of decisions) must be fixed before the event. Particular attention must be paid to crowd management and communication (loud speakers, signs, maps and other plans).

4. All authorities involved in the organization of the event are responsible for the safety of the crowd. The division of responsibility should be regulated in the concept of the event. A mass event should not be approved, if it does not satisfy the applicable safety regulations.

5 The reason for most crowd disasters in the past was a failure to regulate the flow of people in high throughput areas.

6 The organization of an event needs plans for normal operation, but also contingency plans for all kinds of incidents.

7 There are basically three ways of influencing the safety of crowds: design, information, and crowd management.

8 At the Love Parade in Duisburg, the capacity of the main ramp to and from the festival area was given by the minimum usable width of the ramp. Due to two triangular fence structures, ${ }^{52,62}$ which were apparently not shown in the maps, the effective width of the ramp was only 10.59 meters. According to the expert report, this implies a maximum safe flow of 10.59 meters $\times 82$ persons per meter and minute $\times 60$ minutes $=52,103$ persons per hour. However, the maximum expected flow between 17:00 and 18:00 was 145,000 persons per hour, which would require a width of 29.5 meters. Therefore, at the Love Parade in Duisburg, problems with the in- and outflows and a critical accumulation of people had to be expected.

9 Once the crowd density exceeds between 4 or 5 persons per square meter, congestion can build up quickly, which implies high risks for people to stumble or fall (particularly if the ground is uneven). Therefore, injuries can easily happen.

10 People in a dense crowd cannot see what happens a few meters away from them, and they are not aware of the pressure in front. 
11 The density, noise, and chaos in a dense crowd cause a natural desire to leave the crowd. Due to a lack of suitable crowd control and guidance, visitors of the Love Parade in Duisburg could only see a narrow staircase as a possible emergency exit (see Figure 1). When trying to get there, the pressure towards the staircase increased and eventually triggered the crowd disaster.

The analysis of the effective capacity of the main ramp suggests that problems on the ramp were foreseeable, and the question arises, why the obstacles were placed there. However, a complete assessment should also consider the existence of the side ramp (see Figure 1). Moreover, due to the applied access control, the flows on the main ramp did not reach the expected flows by far. This can be directly concluded from the fact that there was never any significant congestion between the two triangular obstacles defining the narrowest part of the ramp, before the flow was controlled in this area from 16:02 on; this is clearly visible in the surveillance videos. ${ }^{62}$ An active bottleneck, in contrast, would be characterized by the formation of a queue [43].

Queues of people did not form in the middle of the ramp, but rather at the upper end, where visitors were trying to enter the festival area. This, however, is not the location where the crowd disaster happened. Therefore, while one had to expect problems in the middle of the ramp where the triangular obstacles were located, the crowd disaster was actually not caused by those obstacles. The course of events that resulted in the crowd disaster involved many contributing factors, as we will show in the following. This conclusion of our study is in line with a quote referring to the Hillsborough disaster of 1989, which apparently goes back to the Archbishop of York and can be found in Keith Still's PhD thesis: ${ }^{5}$ 'Events of the magnitude of Hillsborough don't usually happen just for one single reason, nor is it usually possible to pin the blame on one single scapegoat.... Disasters happen because a whole series of mistakes, misjudgements and mischance happen to come together in a deadly combinations.' This should be kept in mind when Keith Still's expert report on the crowd disaster in Duisburg points out that it is merely based on the evidence presented to him and that it answers only the questions posed to him.

\subsection{Timeline}

The chronology presented in Table 2 is an abbreviated version of the timeline that was originally provided by the organizers of the Love Parade together with their documentary movie. ${ }^{27}$ It is largely supported by the surveillance videos ${ }^{33}$ and other public sources. Additional points will be discussed afterwards.

The video recordings of the surveillance cameras and the related chronology, which were publicly provided by the organizer, end at 16:40 ('in respect of the victims'). Tables 3 and 4 present additional information that is relevant for a reconstruction of the causes of the crowd disaster. A time-ordered, geo-coded video link collection supplementing this paper allows the readers to gain an independent impression. ${ }^{35}$

However, we would like to point out that the times provided on the videos or in the respective video portal may not always be exact. A synchronized video collection is now also available. ${ }^{20}$

\section{Contributing factors}

After the occurrence of a disaster, it is natural to ask, who is responsible. In many cases, people are trying to find one person or organization (the 'scapegoat') to blame. In fact, 
Table 2 Timeline according to the organizers of the Love Parade

\begin{tabular}{|c|c|}
\hline 12:02 & $\begin{array}{l}\text { The festival area is opened. Visitors can enter the area via the access control points from East } \\
\text { and West via the tunnel. }\end{array}$ \\
\hline 13:00 & $\begin{array}{l}\text { The inflow is reduced by closing } 10 \text { of } 16 \text { isolating devices, both on the East and West entrance } \\
\text { towards the tunnel. }\end{array}$ \\
\hline 13:45-14:15 & No important disturbances or queues of visitor flows occur in the entry area. \\
\hline Around 14:00 & Official start of the Love Parade. \\
\hline 14:15-14:30 & $\begin{array}{l}\text { The concentration of visitors increases at the end of the entrance ramp towards the festival } \\
\text { area (due to obstructions by 'floats', i.e. moving music trucks). }\end{array}$ \\
\hline $14: 30-15: 15$ & $\begin{array}{l}\text { The crowd manager tries to order support by the police. The organizer states that the person } \\
\text { responsible for connecting to the police (the 'liaison officer') did not have a working walkie } \\
\text { talkie or mobile phone. }\end{array}$ \\
\hline $14: 30$ & The visitor flow on the ramp and from the West increases. \\
\hline Around 15:00 & Reduction of the visitor flow by closing as many isolating devices \\
\hline 15:12-15:34 & Change of police shifts. ${ }^{63} 5$ police cars drive into the ramp area. \\
\hline 15.21 & $\begin{array}{l}\text { Visitors ignore the fence on the side of the main ramp, following police forces, who have } \\
\text { temporarily opened it. Shortly later, visitors overcome fences also on the other side of the ramp, } \\
\text { which should prevent them from taking the steep slope up to the festival area. }\end{array}$ \\
\hline 15:50 & $\begin{array}{l}\text { A first chain of police forces (police cordon) is formed in front of the side ramp, blocking in- and } \\
\text { outflows in the West (see cordon 1a in Figure 1).64 }\end{array}$ \\
\hline 15:50 & A second police cordon closes the tunnel to the East (see cordon 2 in Figure 1). \\
\hline Aroun & $\begin{array}{l}\text { There is a sudden strong visitor flow towards the festival area from the West. The first police } \\
\text { cordon is moved behind the side ramp (see cordon } 1 \mathrm{~b} \text { in Figure 1). }\end{array}$ \\
\hline From 16:02 & $\begin{array}{l}\text { Police forces start to control the flows to (and from) the festival area in the middle of the ramp } \\
\text { (where the ramp is narrowest due to some fences). }{ }^{65} \text { Queues start to form on both sides of the } \\
\text { resulting bottleneck. } 66\end{array}$ \\
\hline Arour & There are just a few visitors between the three police cordons. \\
\hline $6: 07$ & A jam of visitors forms in \\
\hline Around 16:09 & $\begin{array}{l}\text { A jam of visitors forms above the chain of police forces on the ramp, when trying to exit the } \\
\text { festival area. }\end{array}$ \\
\hline $16: 12$ & $\begin{array}{l}\text { The third police cordon is completed (see cordon } 3 \text { in Figure 1). It stops the in- and outflows } \\
\text { completely, where the fences narrow down the ramp. }\end{array}$ \\
\hline Around 16:13 & The small ramp is opened as entrance to the festival area. Visitors climb over fences. \\
\hline Around 16:14 & $\begin{array}{l}\text { The second police cordon in the East opens up, and visitors enter the area of the big ramp from } \\
\text { below. }\end{array}$ \\
\hline Around 16:17 & $\begin{array}{l}\text { First visitors try to enter the festival area via a narrow staircase connecting the lower part of the } \\
\text { ramp with the festival area on top. }{ }^{68} \text { Afterwards, the staircase is blocked by two security } \\
\text { people. }{ }^{69}\end{array}$ \\
\hline Around 16:21 & $\begin{array}{l}\text { The first police cordon in the West dissolves. }{ }^{19,70} \text { The previously waiting visitors move towards } \\
\text { the ramp and encounter there the dense flow of visitors coming from the East. }\end{array}$ \\
\hline $16: 22$ & First people climb the pole. ${ }^{19,71}$ \\
\hline $16: 22-16: 24$ & $\begin{array}{l}\text { The third police cordon still keeps the ramp closed, while the pressure increases from both } \\
\text { sides (i.e. inflow and outflow). }\end{array}$ \\
\hline $16: 24-16: 28$ & The third police cordon is dissolved. ${ }^{72}$ \\
\hline Around 16:27 & $\begin{array}{l}\text { The narrow staircase is used by people to get up to the festival area. }{ }^{73} \text { Someone climbs on top } \\
\text { of a traffic sign. }{ }^{74}\end{array}$ \\
\hline $16: 31-16: 37$ & $\begin{array}{l}\text { A fourth police cordon is formed in the upper area of the ramp. }{ }^{75} \text { At the same time, the density } \\
\text { in the lower area of the ramp increases steadily. }\end{array}$ \\
\hline After 16:40 & $\begin{array}{l}\text { The situation gets out of control. More and more visitors try to get up to the festival area via the } \\
\text { small staircase, the pole and a container (used by the crowd management, located at the lower } \\
\text { end of the ramp in the South). }\end{array}$ \\
\hline
\end{tabular}

after the Love Parade disaster, it seems that everybody was blaming everybody else: the visitors, the organizers, the police, the city of Duisburg. What makes things difficult is that nobody is totally right and nobody is totally wrong: in the following, we will argue that it is the interaction of many contributing factors that caused the crowd disaster. Before we discuss the interaction of these factors, however, let us shed more light on some of them in separation. While doing so, we will address a number of hypotheses regarding the cause of the crowd disaster, which have been formulated after the event. Given the many victims and pictures reminding of a war zone, some people first thought that a terrorist attack 
Table 3 Further relevant events

\begin{tabular}{|c|c|}
\hline 8:03 & $\begin{array}{l}\text { The police receive an e-mail informing them about the official approval of the Love } \\
\text { Parade. } .^{19}\end{array}$ \\
\hline Until 12:00 & $\begin{array}{l}\text { The construction work (leveling work) of a bulldozer on the festival ground takes longer } \\
\text { than planned and delays the opening of the festival for approximately one hour. }{ }^{21}\end{array}$ \\
\hline 13:33 & $\begin{array}{l}20,000 \text { techno fans are waiting in the West and are creating a lot of pressure to get } \\
\text { in. } 21,76\end{array}$ \\
\hline 13:44 & The police are worried that the access point may be overrun. ${ }^{21}$ \\
\hline Around 14:00 & $\begin{array}{l}\text { A police officer asks the crowd management to make a loudspeaker announcement, } \\
\text { but this cannot be done, because there is no working loudspeaker equipment despite } \\
\text { requirements to have one. }{ }^{21}\end{array}$ \\
\hline ter 14:03 & $\begin{array}{l}\text { Visitors are obstructed by floats (music trucks), while trying to enter the festival area } \\
\text { from the ramp. } 21,77\end{array}$ \\
\hline$: 42$ & $\begin{array}{l}\text { The obstruction by the floats on the festival area causes a jam of arriving visitors on the } \\
\text { ramp almost up to the tunnel. }{ }^{21}\end{array}$ \\
\hline 14:52 & For some time, it is not possible to enter the festival area from the ramp. ${ }^{19}$ \\
\hline 5:06 & The minister of interior visits the crisis management team. ${ }^{19}$ \\
\hline 15:30-18:00 & Mobile phones do not work due to an overload of the mobile phone networks. ${ }^{21}$ \\
\hline rom 15:31 & $\begin{array}{l}\text { Visitors start to climb the slope in the West of the main ramp and one minute later in the } \\
\text { East to get to the festival area. }{ }^{78}\end{array}$ \\
\hline ound 16:00 & $\begin{array}{l}\text { Turmoil and critical crowd conditions occur in front of the access points. A policeman } \\
\text { instructs the crowd management to open the access point in the West. }{ }^{21} \text { The access } \\
\text { point in the East is intermittently opened to reduce the pressure in the crowd. }{ }^{21}\end{array}$ \\
\hline 31 & $\begin{array}{l}\text { A fence at the West side of the tunnel is opened to allow an emergency vehicle to enter. } \\
\text { Hundreds of visitors make use of the occurring gap to enter the tunnel. }{ }^{6}\end{array}$ \\
\hline round 16:30 & Visitors overcome fences in the tunnel. ${ }^{79}$ \\
\hline $6: 43$ & $\begin{array}{l}\text { People scream for help and shout at others they should hurry up; some seem to panic, } \\
\text { but others try to calm them down; the situation changes quickly: people change } \\
\text { between screaming and laughing; some people manage to climb the staircase, but } \\
\text { there is still no continuous flow of people on the staircase. }{ }^{80} \text { People scream they are } \\
\text { about to die. }{ }^{81} \text { The traffic sign is already bent. } 82 \text { People shout from above that those on } \\
\text { the narrow staircase should move on. }{ }^{83}\end{array}$ \\
\hline round 16:36 & Crowd turbulence and critical situation around the pole. ${ }^{84}$ \\
\hline arting 16:38 & $\begin{array}{l}\text { Police are limiting the number of people on the staircase (usually } 2 \text { or } 3 \text { at a time), but } \\
\text { make sure that people do not stop on the staircase. } 85\end{array}$ \\
\hline Around 16:40 & $\begin{array}{l}\text { An unconscious women is passed on to the narrow staircase and elevated up. } 86 \\
\text { A sparse, slowly moving crowd in the tunnel moves towards the festival area. }\end{array}$ \\
\hline arting approx. 16:40 & $\begin{array}{l}\text { Police cars in the city make loudspeaker announcements that the festival area is } \\
\text { completely full and will not be accessible to further visitors anymore until the end of the } \\
\text { day. }{ }^{88}\end{array}$ \\
\hline Around 16:44 & $\begin{array}{l}\text { Some people climb a pole and the narrow staircase next to the ramp (see Figure 1). } \\
\text { Several people try to elevate themselves from the crowd by climbing a billboard. Many } \\
\text { seem to be in trouble between the staircase and the tunnel. }{ }^{89}\end{array}$ \\
\hline 6:47 & $\begin{array}{l}\text { Interview with the Love Parade organizer, who does not seem to be aware how critical } \\
\text { the situation is. } 60\end{array}$ \\
\hline Around 16:48 & $\begin{array}{l}\text { A command is given to stop inflows to the tunnel and the ramp area completely. It is } \\
\text { executed within minutes. }{ }^{21} \text { Sound of police sirens; some people have fallen to the } \\
\text { ground and raise their hands into the air for help. }{ }^{90}\end{array}$ \\
\hline ound 16:50 & $\begin{array}{l}\text { An emergency vehicle is entering the ramp area through the tunnel and opens its } \\
\text { sliding door. An interaction between the crowd and people in the emergency vehicle } \\
\text { takes place. The trouble between the staircase and tunnel is becoming more and more } \\
\text { serious. }{ }^{91} \text { A video from the West looking down on the crowd shows shockwaves in the } \\
\text { crowd. Police forces are having a hard time holding a fence back at the container, which } \\
\text { is used by the crowd management. }{ }^{92}\end{array}$ \\
\hline
\end{tabular}

with explosives had happened. ${ }^{118}$ Others claimed that the fatalities resulted, because some people had fallen on top of others when unsuccessfully trying to climb the stairs from the side or the billboard (see Figure 1). ${ }^{119}$ And again others were blaming the crowd for the outbreak of a 'mass panic' (stampede) ${ }^{120}$ or at least some people for improper behavior. ${ }^{121}$ The first hypothesis was obviously not true. But what about the others? 
Table 4 Further relevant events (continued)

\begin{tabular}{|c|c|}
\hline Starting 16:53 & $\begin{array}{l}\text { The emergency vehicle stops in the middle of the crowd. Strong shock waves occur all over } \\
\text { the crowd and push people to the ground between tunnel and staircase. }{ }^{93} \text { Arms are lifted up } \\
\text { and people are screaming. A group of people is aggressively pushing their way towards the } \\
\text { tunnel (see endnote } \\
\text { others to get toween minutes 1:28 and 1:35). Some people are crawling on top of } \\
\text { the tunnel to allow people to climb up. }{ }^{93,94}\end{array}$ \\
\hline 16:54-17:03 & $\begin{array}{l}\text { Some people get pulled up to the narrow staircase. A ladder is lowered down to the container } \\
\text { at the South end of the ramp, and a woman, who seems to be hurt, is lying down on the } \\
\text { container. } 95,96\end{array}$ \\
\hline Starting 16:57 & $\begin{array}{l}\text { People are pulled up one by one via the container. }{ }^{97} \text { People in the crowd are being pushed } \\
\text { around. A few people climb onto other people, trying to get out of the crowd. A woman is } \\
\text { screaming loudly. }{ }^{98}\end{array}$ \\
\hline Starting 16:58 & $\begin{array}{l}\text { The situation is extremely crowded. Some people scramble up the narrow staircase. Many } \\
\text { people yell for help. }{ }^{99}\end{array}$ \\
\hline Starting 16:59 & $\begin{array}{l}\text { More people are pulled up from the crowded container to the festival area above. Security } \\
\text { guards and police walk along the East side. A police officer is filming. }{ }^{100} \text { An ambulance car is } \\
\text { approaching on the freeway in the West. }\end{array}$ \\
\hline Starting 17:01 & View of emergency forces near the staircase area. ${ }^{101}$ \\
\hline Startin & $\begin{array}{l}\text { People scramble up the stairs. Many people are yelling for help. The situation is extremely } \\
\text { crowded. Police attempt to control the crowd. }{ }^{102}\end{array}$ \\
\hline 17:02 & First victims are reported on the ramp. 6,19 \\
\hline Starting 17:03 & The stairs are clearing slightly, and some people are able to get up. ${ }^{103}$ \\
\hline Starting 17:03 & $\begin{array}{l}\text { A man is trying to grab people and pull them up on the South over the container. Police holds } \\
\text { the fence back. An orange ladder is used to get people out from the container. }{ }^{104}\end{array}$ \\
\hline Around 17:04 & Seven policemen are talking to a few people. Two are helping someone on the ground. ${ }^{105}$ \\
\hline Startir & $\begin{array}{l}\text { A view from the tunnel shows some people climbing up over the container, also with the help } \\
\text { of ropes. It seems that people in the tunnel behind are still reasonably fine. Some of them } \\
\text { appear to be dancing. } 106\end{array}$ \\
\hline Starting 17:05 & $\begin{array}{l}\text { More people are able to get up via the staircase. The density in the ramp area is reduced, and } \\
\text { the police are turning around some people at the back of the crowd, who are still trying to get } \\
\text { to the stairs. }{ }^{107}\end{array}$ \\
\hline Starting 17:05 & $\begin{array}{l}\text { A crowd of people has fallen in front of the stairs, raising their arms up. Some rescue workers } \\
\text { and festival attendees are pulling people out. One policeman tries to hold back the crowd. An } \\
\text { emergency vehicle is guided to the ramp area by the police, coming from the East tunnel. }{ }^{108}\end{array}$ \\
\hline Starting 17:07 & $\begin{array}{l}\text { The stairs are still crowded. Someone is shouting for help by the police. Some policemen on } \\
\text { the stairs help people up. } 109\end{array}$ \\
\hline Starting 17:08 & $\begin{array}{l}\text { Someone is yelling at the police. }{ }^{110} \text { People are pulled out of the fallen crowd, and some } \\
\text { receive first aid. The crowd below the staircase seems 'cleared' by the end of the video, and } \\
\text { there is a considerable amount of police and rescue forces. }{ }^{111}\end{array}$ \\
\hline Starting 17:08 & $\begin{array}{l}\text { People can be seen lying on top of each other. The situation is still crowded, but the density } \\
\text { eventually reduces. }{ }^{112}\end{array}$ \\
\hline Starting 17:09 & $\begin{array}{l}\text { The situation continues to be crowded, but people are starting to move more smoothly up } \\
\text { the stairs. The area around the fallen people empties.113 }\end{array}$ \\
\hline 17:15 & $\begin{array}{l}\text { The operation room of the city of Duisburg does not seem to be aware of the critical situation. } \\
\text { It still calls the Love Parade a big success. }{ }^{114}\end{array}$ \\
\hline Starting 17:16 & $\begin{array}{l}\text { The situation on the ramp has cleared up, but the group of fallen people still seems to be } \\
\text { without professional help. A rescue crew appears in the South-West corner. A person is lying } \\
\text { unconsciously on the ground. Many people try to resuscitate others. Fallen visitors are pulled } \\
\text { out of the pile of people. }{ }^{115}\end{array}$ \\
\hline Around 17:20 & $\begin{array}{l}\text { The crowd has mostly dissolved. Fire and ambulance cars are parked in the South of the ramp. } \\
\text { A woman tries to provide first aid to a man in the South-West corner. At least } 2 \text { other people } \\
\text { provide first aid to people on the ground. }{ }^{116}\end{array}$ \\
\hline Around 18:00 & $\begin{array}{l}\text { It is decided not to terminate the Love Parade to avoid further critical situations (by evacuating } \\
\text { the festival area too quickly). } 6,19,117\end{array}$ \\
\hline
\end{tabular}

\subsection{Did the crowd panic?}

When talking about crowd disasters, public media often use the term 'mass panic', which suggests the occurrence of a stampede as reason of the disaster (see endnote ${ }^{122}$ and also the name of the link in endnote ${ }^{11}$ ). This suggests that crowd disasters happen, because the crowd 'goes mad' [44]. There certainly exist some instances of this kind (such as the 
stampede in Baghdad on August 25, 2005, due to spreading rumors of an imminent suicide bombing in the crowd, ${ }^{123}$ or the stampede in a Chicago night club triggered by rumors of a poisonous gas attack). ${ }^{124}$ However, the hypothesis of a 'psychological state of panic' as reason of crowd disasters has been questioned many times [45, 46].

What evidence do we have for the Love Parade disaster in Duisburg? Has the crowd 'gone mad' because of influence of alcohol and drugs or because of impatience to get on the festival area? At first sight, one may think so, given that a number of visitors climbed over fences, up the pole, and on the container to reach the festival area. However, as we will see, these activities started at a time when people on the ramp were already exposed to crowded conditions.

Let us discuss this in more detail. The first problems with visitors overcoming fences were reported around 15:31. ${ }^{78}$ However, there were reports as early as 13:40 (see Table 3), which show that people waiting for access had difficulties to breathe and asked to open the emergency exits (which did not happen). ${ }^{125}$ These problems demonstrate that the access capacity was far below demand.

Problems related to queues of people aggravate when queues are long and broad, so that little or no progress is visible. In such situations, people will subconsciously reduce their distance eventually. Although the reduction of distance might be negligible, the socalled 'queuing effect' will create the impression of progress. However, it will also cause a compression of the crowd [47]. When the distance is small, there will be inadvertent body contacts, which can add up and cause unintentional pushing. Note that the transition from an acceptable situation with rare body contacts to a stressful situation with frequent contacts can happen quite abruptly, i.e. the people in the crowd, security forces and police might not expect this sudden transition [48]. People may interpret the situation as intentional pushing, which may trigger stress and aggression. At a certain density, it may also be required to push others away in order to be able to breathe [36]. ${ }^{125}$

If people have to wait long and are not informed about the reasons for this, they will become impatient and may eventually start to push intentionally (because they assume that progress can be accelerated). While most impatient pushing happens in the middle of the queue, the situation usually becomes most critical at the front of the queue (but the people who push cannot see this, and they experience much less crowded conditions).

The situation is particularly bad behind bottlenecks. These can create 'traps' without any possibility to escape. Such situations must generally be avoided. This also means that flow control is not a solution for every problem. It requires suitable designs and an adaptive operation.

According to our assessment, it had to be expected that the access points would have to be opened and fences would eventually be overcome, given that the festival area and the inflow capacity were small (in particular as the access was delayed by leveling works). Waiting times often amounted to several hours, and access to entertainment, food, water, and toilets must have been quite limited outside the festival area.

Nevertheless, the problems on the ramp were even more serious than at the access points. They were related to the low inflow to the festival area (see Table 1). An analysis of surveillance videos suggests that the floats (i.e. the moving music trucks) 'pulled' visitors along with them, as expected by the planners, but this was not apparently effective enough. After the crowd disaster, it was sometimes claimed that the floats even obstructed the inflow of arriving visitors. While the inflow never stopped completely before the cordons 
were established, ${ }^{126}$ the queue forming at the top of the ramp varied considerably over time. ${ }^{126,127,128}$ The inflow was particularly low, when a float was slowed down or stopped around 15:31 in the neighborhood of the ramp. ${ }^{129}$

While the organizers considered the possibility of inflow problems, ${ }^{18,60}$ they assumed that these could be handled by 'pushers' ${ }^{130}$ at the upper end of the ramp and that the floats could be used as well to reduce them (by attracting the crowd onto the festival area and moving it along with them) ${ }^{18}$ However, there was apparently a lack of a sufficient number of pushers ${ }^{21}$ and the floats did not manage to overcome the inflow problem. It looks like the floats were slowed down by the dense crowd, which in turn obstructed the inflow of visitors, thereby creating an unfavorable feedback loop. The situation was particularly tense from 14:27 to 15:05 and from 15:55 to 17:00; as a consequence, the crowd manager asked for support by the police at 15:16 (or before). ${ }^{6}$ The responsible officer arrived around 15:30, when a jam had formed on the upper part of the ramp. ${ }^{39}$ About 10 minutes later, a joint strategy was found. However, already at 15:31 (i.e. at the time when one of the floats slowed down in front of the ramp), the situation had deteriorated so much that a large amount of visitors decided to overcome fences along the ramp to reach the festival area via the grassy slopes on both sides (see Figure 1). ${ }^{78,126,127}$ This mitigated the bottleneck situation at the end of the ramp, which could have caused serious problems at a much earlier time. In fact, it seems that the dangerous phenomenon of crowd turbulence (see Sec. 3.4) first occurred in the upper part of the ramp. ${ }^{128}$

According to Table 3, the first visitors used the narrow staircase at 16:17, and around 16:22 the first people climbed the pole on the East side of the lower ramp area, to get up to the festival area. ${ }^{38}$ The first people climbed the container of the crowd management on the South of the ramp at 16:24. ${ }^{131}$ This was the time, when the third police cordon is given up. While the initial flow on the staircase was stopped by police, people used the staircase again around 16:27. At about the same time, a person climbed a traffic sign on the ramp (see Figure 1) ${ }^{74}$ All of this might have been interpreted by the security as signs of an excited crowd that did not behave properly, but the temporal coincidence of these events clearly shows that people were trying to escape from the crowd in any possible way, because they felt in danger. In fact, behavior of the crowd that might have been perceived as 'improper' occurred mainly, after the first two cordons had to be given up (around 16:14 and 16:21), while the third one was still closed, which caused an increasingly crowded situation on the ramp.

In videos recorded at the Love Parade, the phenomenon of crowd turbulence starts to appear between 16:34 and 16:36. ${ }^{84}$ Around the same time one can hear painful shouts, and some people scream for their lives and for help (see Table 4). ${ }^{81}$ In this situation, at least some people must have experienced a psychological state of panic. Nevertheless, there were no signs of sudden systematic movements of the crowd into a certain direction, which would indicate a stampede, and no people 'crawled' on top of others, yet. Around 16:40, the forces in the crowd were so critical that a traffic sign was bent, ${ }^{83}$ and an unconscious women was passed on to the narrow staircase. ${ }^{86}$ Around 16:45, several people tried to elevate themselves out of the crowd by climbing a billboard next to the traffic sign. ${ }^{89}$ Approximately at the same time, many people between the billboard and the staircase raised their arms into the air (the movie should be watched in full screen mode to see this well). ${ }^{90}$ This is usually a sign that they have fallen to the ground and are seeking help from others to get back on their feet. We believe that this was the first sign that people were 
dying or likely to die. At 16:51, an emergency vehicle entered the ramp, but it was taking care of other problems. ${ }^{38}$ Still, there were no sudden moves into one direction visible in the crowd that would speak for a stampede. Rather, people next to those screaming for their lives were trying to calm them down by saying 'you will make it,' and offering them water. ${ }^{132}$ Around 16:55, a group of people was pushing their way through the crowd towards the tunnel in the West (in the video in endnote ${ }^{93}$ this can be seen between 1:28 and 1:35 in full screen mode; the same shows up in this video ${ }^{133}$ ). Around the same time, some people were trying to 'crawl' over others, hoping to escape the situation. ${ }^{93,94}$ While this was clearly a relentless and potentially harmful behavior, it is not obvious that it killed others, and it occurred under circumstances that were absolutely life-threatening (which should not be misunderstood as a justification of such relentless behavior). First deaths were reported at 17:02.6,19

\subsection{Were people killed by others falling on them from above?}

As most people died between the staircase and the billboard, ${ }^{19}$ the public media initially assumed that they were victims of others, who had fallen down after unsuccessfully trying to climb the staircase from the side or to climb the billboard. ${ }^{119}$ There was even a statement that the staircase should have been 'blasted away' before the event. ${ }^{134}$ However, the videos viewed by us do not provide convincing evidence that falling people were the cause of the disaster. It is also not plausible that a few people falling from the staircase could account for 21 fatalities and more than 500 injured people. ${ }^{11}$ Moreover, the height of falling was not large, and most victims were not lying on the side of the staircase, but rather between the staircase and the entrance of the tunnel (see 'accident area' in Figure 1). ${ }^{135}$

Nevertheless, the analysis of the video materials and photographs witnesses at least three events of falling people. According to endnote ${ }^{19}$, the first one happened around 16:57 at the billboard, the second shortly later at the same place. The third incident happened at the same location at 17:03. Furthermore, one person failed to climb the staircase from the side; around 16:40 it fell back to the ground from a low elevation. ${ }^{136}$ Apparently, the height of falling was relatively small, and the falling people also did not trigger a stampede of the crowd. Therefore, according to our judgment, it is unlikely that people died as a direct consequence of others falling down from the staircase or billboard.

\subsection{Did the staircase cause a crowd crush?}

Nevertheless, it is a valid question, whether it was a mistake to let people use the staircase. It is likely that people were turning towards the staircase, hoping that it would provide a chance to escape, and that even a minor movement could seriously increase the local pressure in the crowd, given the high density that had already built up on the ramp. In fact, the situation in the crowd was highly problematic not only next to the staircase, ${ }^{37}$ but also next to the pole, ${ }^{84}$ and it was apparently the use of the pole that inspired the use of the staircase. ${ }^{137}$ Nevertheless, the movement of the crowd towards these improvised 'emergency exits' was not large. The videos we have seen do not show the sudden start waves, which are typical when a waiting crowd (or jammed traffic) starts moving [43, 47]. Therefore, we doubt that the fatalities were caused just by a relentlessly forward pushing crowd, which crushed the people. Crushing due to extreme densities rather happens when a large crowd moves too quickly towards a narrowing [29]. In Duisburg, however, the crowd disaster happened in a crowd that barely moved forward. Even though the situation 
on the ramp was critical for the crowd from $16: 35$ on, ${ }^{38}$ it seems that most people had a chance to breathe (at least intermittently) and to recover between stressful periods. In fact, the recordings change many times between screams of panic and more positive noises.

We do not question that the density in the crowd became so high at some locations that it could seriously harm health and lives, but it is puzzling that most victims were not found on the side of the staircase, or next to the pole(s) and the container, where they had to be expected in case of a crowd crush. We also do not deny that the staircase was an attraction point, but we doubt that it can be seen as immediate cause of the disaster. It may have even played a significant role for the evacuation of the overcrowded ramp, since it served as emergency exit. However, this emergency exit was used too late and not very efficiently. A continuous flow of people on the staircase was established only around 16:40..$^{38,132}$ Before, it stopped or was blocked many times. The same happened during the most critical period, when many people tried to climb the staircase from the side, which considerably obstructed the flow on it. ${ }^{138}$

\subsection{Occurrence of crowd turbulence}

So far, the cause of the crowd disaster in Duisburg has still not been revealed. If the crowd did not panic, and people did not die from others falling on them, and a rush towards the narrow staircase did not cause the crowd disaster, what then was the reason for it? The answer lies in the dynamics of the crowd, which unintentionally emerged, when the density became too high. John Fruin describes the situation as follows [7]: 'At occupancies of about 7 persons per square meter the crowd becomes almost a fluid mass. Shock waves can be propagated through the mass, sufficient to... propel them distances of 3 meters or more.... People may be literally lifted out of their shoes, and have clothing torn off. Intense crowd pressures, exacerbated by anxiety, make it difficult to breathe, which may finally cause compressive asphyxia. The heat and the thermal insulation of surrounding bodies cause some to be weakened and faint. Access to those who fall is impossible. Removal of those in distress can only be accomplished by lifting them up and passing them overhead to the exterior of the crowd.'

In fact, suffocation was diagnosed as the reason for the death of people during the Love Parade disaster. ${ }^{12}$ In simple words, this means that the lungs of the victims have been compressed so much that they were unable to breathe enough to get the required amount of oxygen to survive. Compressive asphyxia was also identified as cause of death in many other crowd disasters.

According to recent studies [48], it is often not the density alone that kills ('crushes') people, but the particular kind of dynamics that suddenly occurs when the density becomes so high that physical interaction between people inadvertently transfer forces from one body to others. Under such conditions, forces in the crowd can add up. Force chains may form, such that the directions and strengths of the forces acting on the body of an individual in the crowd are largely varying and hard to predict. As a consequence, an uncontrollable kind of collective dynamics occurs in the crowd, which is called 'crowd turbulence' or 'crowd quake' $[12,48]$. The forces in this dynamical state of the crowd can cause various injuries (in particular of the chest, as in crowd crushes). They are so high that they cannot even be controlled by large numbers of police forces. Individuals can handle the situation even less. They are exposed to a large risk of losing balance and stumbling. ${ }^{139}$

Once people have fallen, they constitute obstacles to others and are endangered by others falling on top of them, since these can also not control their steps anymore as they 


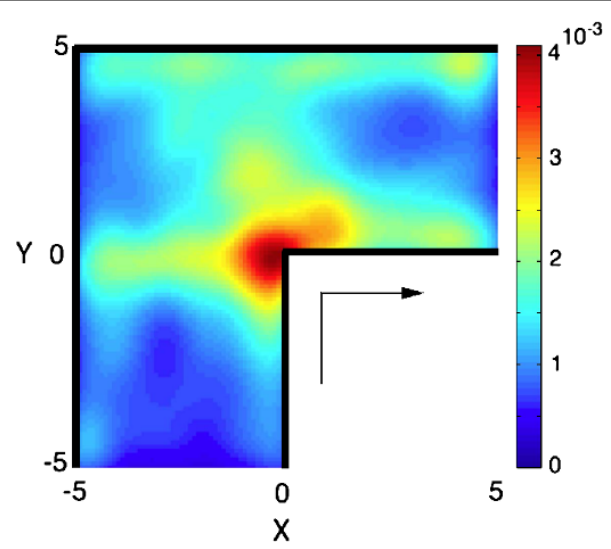

Figure 2 Computer simulation of a densely crowded area with the heuristic pedestrian model of Ref. [27] (figure from the Supporting Information). Orange and red areas indicate the locations with the highest crowd pressure, when a densely packed crowd tries to move around the corner. The simulated situation is analogous to leaving visitor streams at the Love Parade in Duisburg, trying to leave the main ramp through the tunnel in the West. Note, however, that the above simulation does not consider inflows of visitors arriving from the East. These would move the high-pressure area a bit up the ramp, where the accident actually happened.

wish. Hence, the surrounding people are likely to stumble as well, which creates a 'domino effect. ${ }^{140}$ The resulting number of falling people may be large. This creates a heap of people, in which nobody can easily get back on their feet again. Those on the bottom have serious difficulties to breathe, and they are likely to suffocate if this state lasts too long, given the weight of others on their top.

Directly after the Love Parade disaster, when the situation was far from clear, one of the authors conjectured that 'crowd turbulence' was the likely cause of the fatalities. ${ }^{141}$ Eye witness reports and the analysis of video recordings confirms this hypothesis. ${ }^{142}$ Crowd turbulence can be observed in the crowd at least from about 16:34 on around the pole and from 16:39 on in the lower part of the ramp. ${ }^{143}$ Before 16:48, a considerable number of people fell to the ground between the tunnel and the staircase, ${ }^{90}$ approximately at locations where computer simulations predict the largest crowd pressures (see Figure 2). ${ }^{144}$ The situation deteriorated further around 16:53, when crowd turbulence affected almost the entire width of the ramp, ${ }^{93}$ i.e. hundreds or even thousands of people were irregularly moved around by the pressure in the crowd; many of them stumbled and fell on top of each other. ${ }^{93}$ The troubled area agrees with the one, where most victims were found. ${ }^{135,145} \mathrm{Un}$ der the weight of others lying on them, they must have eventually suffocated, since there were not enough emergency forces to help them back on their feet in time.

Public blogs have been wondering about the reasons for the layered crowd of fallen people: ${ }^{146}$

- Did the emergency vehicle driving on the densely crowded ramp trigger the falling?

- Was there a fence lying on the ramp, that should have covered a broken manhole cover? ${ }^{147}$

While cars moving through a dense crowd can indeed trigger critical conditions, it seems that people had already fallen to the ground (around 16:48), before the emergency vehicle arrived on the ramp (around 16:50)..$^{38,148,149}$

A broken manhole cover or any kind of obstacle lying on the ground would certainly have made it difficult for people to keep their balance and stay on their feet, when pushed 
around by turbulent waves. Such obstacles are dangerous and should certainly not have been located in the bottleneck area (the ramp). While, even without obstacles, it is likely that crowd turbulence would have caused people to fall sooner or later, obstacles can act as 'nucleation points' and thereby possibly trigger an earlier falling of people, which may reduce their chances of survival.

\section{Causal interdependencies}

We must now discuss the question, how the conditions, which caused the deadly crowd turbulence, have come about.

\subsection{Failure of flow control}

When viewing the area of the Love Parade in Duisburg (see Figure 1), the choice of location appears surprising, since the festival area was relatively small and furthermore constrained by railway tracks on one side (in the East) and by a freeway on the other side (in the West). This becomes particularly clear when comparing the area with the one used during the Love Parades in Berlin. ${ }^{150}$ As this circumstance implied a risk and the bottleneck at the ramp during peak hours was foreseeable (see Sec. 2.2), flow control was crucial for the safety of the Love Parade. However, there was a whole avalanche of problems that accumulated and, thereby, caused the crowd disaster.

The first problem on the day of the Love Parade occurred when the opening of the festival had to be delayed by approximately one hour due to a delay in the completion of the leveling work (see Table 3). Therefore, many visitors must have been queued up already at the time when the festival area was opened. It seems that the organization of the mass event could never make up for this delay.

The overall inflow capacity was apparently further reduced through obstructions by the floats, which had probably not been anticipated to that extent (see Sec. 3.1). As a consequence of this, access control was necessary already at 13:00 (see Table 2), much before the expected peak hours. This further increased the queues and the waiting times. The following quote witnesses the problems: ${ }^{151}$ 'We parked the car about 3 kilometers away from the freight station (next to the festival area), and it took us almost 5 hours (!) to get to the Love Parade (festival area). On the way, we were facing blocked roads time and again, fences were carried over us, emergency forces could not get through, people collapsed,....

Clearly, visitors of the event must have become impatient, particularly because there was probably a lack of food, drinks and toilets outside of the festival area (since such long waiting times were not anticipated). One could, therefore, expect that it would be difficult to control the inflow. In this connection, it is also worth noting that there was not much entertainment outside the festival area to shorten the psychological waiting time and to relieve stress and impatience. Apparently, there was a stage outside the festival area, which was supposed to absorb some of the visitors, who could not get to the festival area, but for some obscure reason, it was moved to another area, where it attracted only a smaller number of people. ${ }^{21}$

Between 14:30 and 15:10, the organizers found it difficult to control the inflow with the isolating devices (see Table 2). This was probably not just a result of the excessive waiting times, which caused impatience, but possibly also because some of their security people were needed elsewhere (e.g. to improve the outflow from the ramp or to guide VIPs) ${ }^{21}$ As a consequence, the organizers tried to get support by the police. ${ }^{21}$ 
For a number of reasons, it seems to have taken a considerable amount of time to get the requested police support. Communication by walkie talkies and mobile phones did not work reliably. ${ }^{21}$ There were also no functioning loud speakers at the ramp, as there should have been. ${ }^{21}$ Moreover, there was a change of police shifts between 15:12 and 15:34, when the situation started to deteriorate. ${ }^{21}$ Various reports suggest that police and organizers were not well coordinated, probably due to the afore-mentioned communication problems. It is also likely that the following emergency operations had not been exercised before. As a consequence, the police may have tried to solve the problem with concepts they were familiar with. They formed several police cordons for flow control. This tactic is often applied to get control of violent crowds. However, it failed during the Love Parade, and we will now analyze why.

\subsection{A lack of overview of everybody}

As was pointed out in Sec. 2.3, when the crowd was trapped in a situation of extreme density, it did not have a chance to get an overview of the situation and possible ways to improve it, in particular to get out of the area. Signs and loudspeaker announcements were not available. The only possible emergency exits they could recognize were the narrow staircase, the pole(s), and the container of the crowd management. They were used accordingly, which was quite reasonable in the more and more dangerous situation that the crowd found itself in.

At this time, all the hope to get control of the situation rested on the police. The police may have been surprised by the sudden need to take control, which was requested by the crowd manager when difficulties to access the festival area occurred at the upper end of the ramp. The police tried to solve the problem by establishing cordons, but it was soon noticed that police cordons 1a, 2, and 3 (see Figure 1) blocked not only the inflow, but the outflow as well. This is also the reason why cordon 1a was moved behind the side ramp (see cordon $1 \mathrm{~b}$ in Figure 1), and why police cordon 4 was formed at the upper end of the ramp (after dissolving cordon 3). This would have allowed to re-direct the outflow via the side ramp. However, before these operations could be completed, cordons $1 \mathrm{~b}$ and 2 had to be given up because of the increasing pressure in the waiting crowd, while cordon 3 was still there. ${ }^{6}$

It is known that dense counter-flows are unstable and may give rise to mutual blockages, which can cause crowd disasters $[8,49]$. For such reasons, it is recommended to separate the flow directions at mass events. Yet, it was not the instability of dense counter-flows which caused the incident in Duisburg. The lack of directional flow separation, however, did not allow one to clear the ramp, after it became crowded by the dissolution of two of the cordons. When cordons $1 \mathrm{~b}$ and 2 had to be given up, the police suddenly found itself in a situation, where in- and outflows blocked each other, and it was basically impossible to evacuate the ramp in conventional ways, when people quickly accumulated on both sides of cordon 3. A trap without exits or emergency exits resulted, from which people could not get out, and the situation kept getting worse. ${ }^{152}$

For people in the crowd, it was impossible to gain a sufficient overview of the situation and to find a solution. Police had helicopter surveillance ${ }^{153}$ and was filming the ramp from the top. However, it took some time until the criticality of the situation was noticed and evacuation measures were taken. When the evacuation finally became effective, the ramp cleared quickly. ${ }^{116}$ But prompt action was delayed by communication problems. It 


\section{Table 5 Course of events as presented in the police report ${ }^{6}$}

\begin{tabular}{|c|c|}
\hline $\begin{array}{l}14: 27-15: 05 \\
15: 55-17: 00\end{array}$ & $\begin{array}{l}\text { Queues of arriving visitors form at the upper end of the main ramp, which leads to the festival } \\
\text { area. For this case it was planned (1) to use 'pushers' in order to make the people move } \\
\text { forward, (2) to close the access points in the East and West in front of the tunnels, (3) to make } \\
\text { loudspeaker announcements [pp.20+13]. }\end{array}$ \\
\hline 15:16 & The crowd manager asks for police support via the liaison officer [p.31]. \\
\hline Around 15:30 & The relevant police officer arrives at the container of the crowd manager [p.31]. \\
\hline 15:30-15:40 & $\begin{array}{l}\text { Crowd manager and this police officer jointly decide (1) to ask crowd management/security } \\
\text { staff to work as 'pushers' in order to ensure a better inflow into the festival area from the upper } \\
\text { end of the ramp, ( } 2 \text { ) to close the access points for approximately } 10 \text { minutes, (3) to form a } \\
\text { cordon in the middle of the ramp in order to shield visitors trying to enter the festival area } \\
\text { from behind [pp. } 20+31] \text {. }\end{array}$ \\
\hline 15:45 & $\begin{array}{l}\text { In the discussion with other police officers, this plan is modified towards forming } 2 \text { police } \\
\text { cordons in the tunnels to the West and to the East [p.22]. }\end{array}$ \\
\hline 15:50-16:20 & $\begin{array}{l}\text { Police cordon } 1 \text { is formed in the tunnel in the West (first before the side ramp and then after it } \\
\text { from 16:02 on in order to allow people to use the side ramp) [p.21]. }\end{array}$ \\
\hline 15:57-16:16 & Police cordon 2 is formed in the tunnel in the East [p.21]. \\
\hline 16:01-16:24 & $\begin{array}{l}\text { A third police cordon is formed in the middle of the ramp in order to avoid that visitor flows } \\
\text { returning from the Love Parade would undermine police cordons } 1 \text { and } 2 \text { from behind } \\
{[p .21+22] \text {. }}\end{array}$ \\
\hline Around 16:10 & $\begin{array}{l}\text { When arriving at the relevant area of the ramp, the responsible officer discovers that (1) many } \\
\text { people are trying to leave the festival area and (2) the expected dissolution of the jam at the } \\
\text { upper end of the ramp did not happen within the } 10 \text { minute time period foreseen for this. } \\
\text { Therefore, the blockage of the inflows by cordons } 1 \text { and } 2 \text { must be maintained longer than } \\
\text { planned. Due to this delay and since the access points must be intermittently opened, the } \\
\text { pressure on police cordons } 1 \text { and } 2 \text { becomes so high that they must be given up [p.23]. }\end{array}$ \\
\hline $16: 24$ & $\begin{array}{l}\text { Visitors are jammed up on both sides of police cordon } 3 \text {. The situation becomes extremely } \\
\text { crowded [p.24]. Therefore, police cordon } 3 \text { is dissolved, also because it is 'ineffective' between } \\
\text { two oppositely directed flows [pp.24+34]. }\end{array}$ \\
\hline $16: 31$ & $\begin{array}{l}\text { A new (transparent) police cordon is formed at the upper end of the ramp from } 16: 31 \text { on } \\
{[\mathrm{pp} .21+24] \text {. It serves to stop the outflow of leaving visitors via the main ramp and to encourage }} \\
\text { arriving visitors to use the slopes to enter the festival area (see Figure 1). }{ }^{5,156} \text { [pp.24+34] }\end{array}$ \\
\hline 16:39 & The fire brigade reports 'panic-like' movements on the ramp with some over-run people [p.25]. \\
\hline 16:40-16:55 & $\begin{array}{l}\text { The festival area is closed for newly arriving visitors (by moving vehicles in front of the access } \\
\text { points) [pp. } 25+35] \text {. }\end{array}$ \\
\hline $\begin{array}{l}\text { After } \\
\text { evacuation of } \\
\text { ramp area }\end{array}$ & $\begin{array}{l}\text { Some densely crowded spots remain around the container, two poles and the narrow } \\
\text { staircase. It is not possible to redirect them by words or gestures [pp.34+35] }\end{array}$ \\
\hline
\end{tabular}

The numbers in square brackets correspond to the page numbers of the report.

seems that the first loudspeaker announcement could only be made around 17:30, after a loudspeaker vehicle had entered the ramp. ${ }^{154}$

Why did the evacuation start so late? The analysis of the police is presented in Table 5 . It seems that first attempts to direct the crowd towards the upper end of the ramp started around $16: 40,{ }^{19,155}$ but were not very effective. ${ }^{6}$ It is true that evacuation attempts take some time, but there was also a lack of efficient means of communication (such as loudspeakers or megaphones). Moreover, we would like to point out the following: In crisis situations, decision-makers are often overwhelmed by the pace of events [50], mainly for two reasons: First, it takes time to collect information locally, and bring it to the attention of the chief police officer, who then takes a decision and gives commands. These are then transmitted down to the local police forces through the command chain. Second, critical situations are often characterized by incomplete, contradictory, and ambiguous information, which makes it difficult to assess the situation correctly and come to the right conclusions.

When the situation on the ramp became unbearable and life-threatening, people started to escape via the pole, the container and the staircase next to the ramp. This could have 
been misinterpreted as aggressive attempts of impatient visitors to storm the festival area, but in reality, it was a sign of emergency. However, due to the noise level, screams for help ${ }^{98,99}$ were hard to comprehend. Also visitors (on the East), looking on the ramp from above around 16:30 did not have a sense of emergency. ${ }^{157}$ This makes it understandable, why pressure relief operations were not yet effective, when the crowd disaster was about to start.

Once the evacuation process on the ramp started, the area emptied quickly. ${ }^{116,156}$ The narrow staircase also might have played an important role as an emergency exit at this time. ${ }^{132}$ Others managed to leave the ramp towards the festival area, following the emergency vehicle. ${ }^{158}$ However, people close to the staircase were still focused on it. ${ }^{137}$ This might have been a result of the 'tunnel vision' that develops when people are stressed. Even when the surrounding crowd had dissolved, it took a long time, until those who had fallen to the ground between the tunnel in the West and the staircase got back on their feet, if they managed this at all..$^{93,145}$ In fact, many of them were injured or died.

A lack of overview is typical for crises situations. During the Love Parade disaster in Duisburg this is, for example, reflected by the fact that, around 15:06, the minister of interior visited the Love Parade (see Table 3), but despite first signs of overcrowding, he left the festival area before the incident. At 16:47, the organizer gave an interview, which still called the event a success, ${ }^{60}$ and as late as $17: 15$, the city's situation room made a similar statement. ${ }^{114}$ Emergency forces were also responding late. As a consequence, a triage procedure had to be applied. (This procedure is typical for war zones, major disasters, and terrorist attacks.) Therefore, many people in critical health conditions did not get first aid. $^{159}$

\section{Discussion}

In the following, we try to gain an integrative view of causal factors of the crowd disaster, which strictly needs to be distinguished from a legal analysis or a determination of responsibilities. We also want to stress that the main purpose of our analysis is to learn for the future, i.e. to identify factors that need to be paid more attention to.

\subsection{Resilience, systemic instabilities, and cascading effects}

Note that, generally, a good organizational concept should be resilient ('forgiving'), i.e. it should be robust to mistakes and complications. Therefore, many disasters do not have a single causing factor. They are a result of interaction effects. This also applies to the Love Parade disaster which, as we will argue below, can be understood as result of a systemic instability. ${ }^{160}$ The term 'systemic instability' is used here for situations, where small perturbations can trigger a series of events through mutual amplification effects in a way that things eventually get out of control, even if everyone makes best efforts. At the Love Parade, people were dying although nobody wanted this and everyone was trying to prevent the death of people. Other examples for systemic instabilities are

- spontaneous breakdowns of traffic flows above a certain critical density (even when everyone is driving in a circle and trying hard to maintain a finite speed) [43, 51],

- breakdowns of cooperation in social dilemma situations, which give rise to 'tragedies of the commons' [52],

- political revolutions [53-55] and

- financial breakdowns. ${ }^{161,162}$ 
Many systemic instabilities come along with cascading effects, which tend to create extreme events [56,57]: the overload of one component of the system challenges other components, which therefore causes a propagation of problems through the system. Usually, cascading effects do not occur during normal operation, but are triggered by (random) perturbations or the coincidence of several complicating factors. They tend to occur when the interdependencies in the system exceed a critical strength. For example, cascading effects are observed in traffic jam formation (when the density is too high) [43], blackouts of power grids, for many kinds of disasters [58], for the current financial crisis, ${ }^{158}$ and for the Arab Spring revolutions [53-55].

\subsection{What caused the crowd disaster: causal interdependencies of contributing factors}

The following analysis discusses cascading effects that have (most likely) contributed to the Love Parade disaster in Duisburg (see Figure 3 for an illustration).

- Berlin rejects to host the Love Parade (LP), and other cities take over. ${ }^{12}$ The Love Parade moves from city to city, which creates new organizational challenges each time (in more difficult locations than in Berlin with its wide roads and expansion areas).

The change of organizational teams makes it difficult to accumulate crowd management experience over many events.

- Bochum has to cancel its Love Parade, because it cannot manage the security challenges. $^{12}$

- Duisburg/Essen is elected as cultural metropole 2010. ${ }^{163}$ It is under pressure to come up with an attractive cultural program. This seems to have created a desire to approve the Love Parade. ${ }^{21,51}$

- The festival area does not provide capacity reserves and implies a number of organizational difficulties. In the tunnel and on the ramp, in- and outflows are not separated, and there is no separate route for emergency vehicles (i.e. they have to use the tunnel as well).

- To overcome security concerns, an evacuation study is commissioned. It mainly focuses on evacuation scenarios, ${ }^{18}$ assuming a maximum concurrent number of visitors as it was required by the security concept of the city. ${ }^{21,164}$

- Due to the late approval of the event (see Table 3), the security concept may have been finished 'last minute' (and vice versa). The likely consequence is that contingency plans may have been insufficient and could not be exercised enough. There was probably also not enough time to ensure a good coordination between organizers and police forces.

- Due to delays in finishing the leveling work (see Table 3), the festival area of the Love Parade is opened later than expected. ${ }^{165}$ This implies an early overload of the access points and causes an impatient crowd (particularly as facilities, supply and entertainment were probably scarce outside the festival area).

- People enter the Love Parade area later and return earlier than expected.

- The interaction of the floats with the crowd does not enable a sufficient inflow to the festival area. This apparently requires that crowd management forces are moved away from the isolating devices to the end of the ramp, in order to improve the inflow; requested VIP support seems to absorb some manpower as well. ${ }^{21}$

- The crowd management faces problems to control the isolation devices, and it tries to organize police support. ${ }^{21}$ 


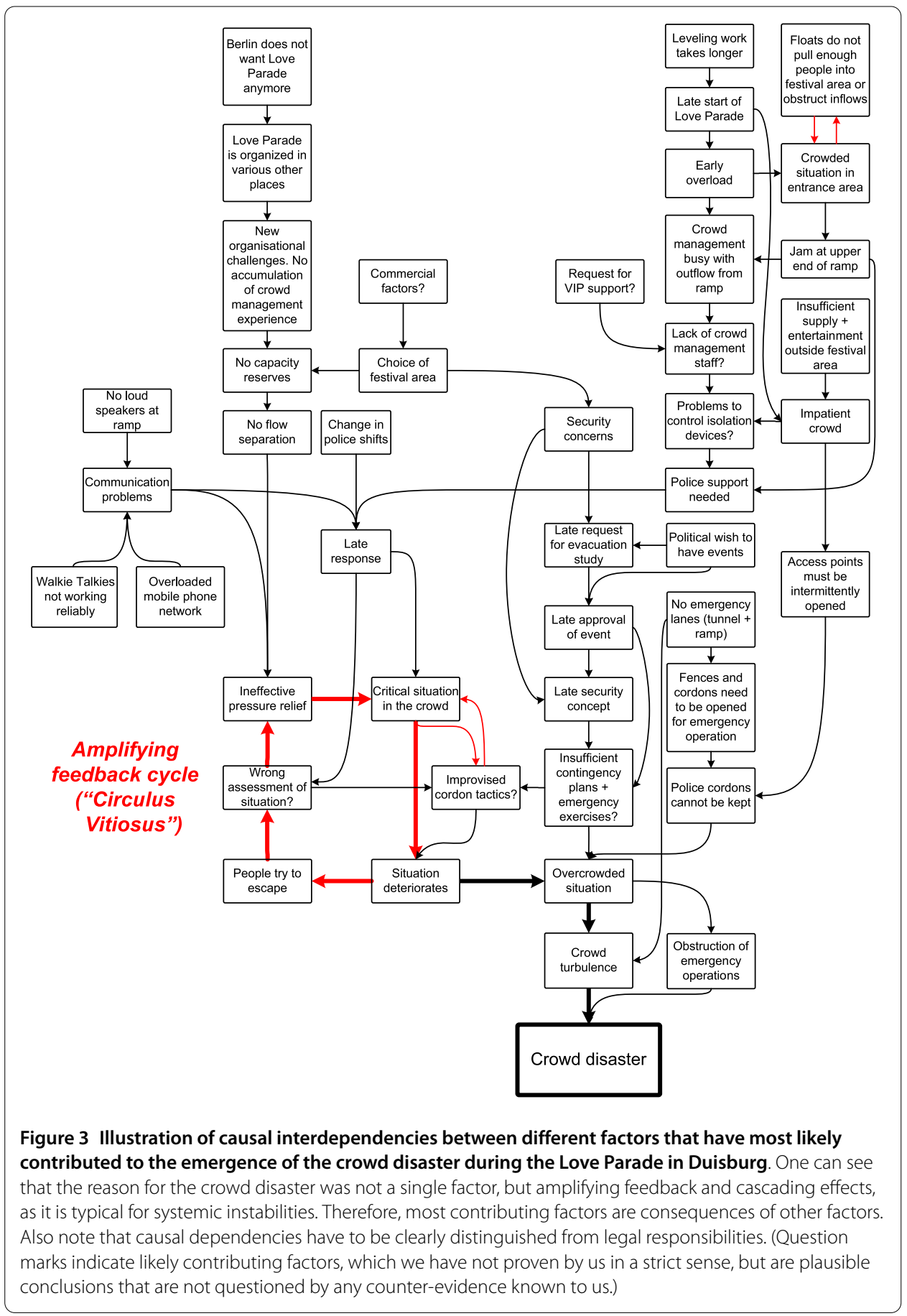

- There are difficulties in the communication and coordination between organizers and police. Suitable communication means are missing or not used or are not working in a reliable way. ${ }^{21}$ Therefore, the feedback between the situation, the crowd management, and the crowd is insufficient.

- Due to communication problems and a change in police shifts, police support may have been delayed. ${ }^{21}$ Moreover, it must have been difficult for the new shift to get an overview of the situation. 
- Maybe due to the urgency of the situation, it is decided to form two police cordons in the tunnels leading to the ramp. A third police cordon is established in the middle of the ramp, where fences narrow down the diameter of the ramp. It shall prevent that leaving visitors undermine the police cordons in the tunnel from behind. ${ }^{6}$

- The police cordons in the tunnel are given up, probably because of the high pressure of the arriving crowd. This replaces the problem at the upper end of the ramp by an even bigger problem in the middle of it: A lot of visitors are moving into the lower ramp area through the tunnel, while many others are waiting at the upper end to leave the event. As the third cordon blocks in- and outflows, jams of arriving and leaving visitors are quickly growing on both sides of cordon 3 . The cordon is dissolved, because it is ineffective, and a new police cordon is formed at the upper end of the ramp.

- At this time, the situation in the crowd is already critical. The lack of separation of opposite flow directions makes it difficult to let people out without letting people in. ${ }^{165}$ Therefore, it is impossible to evacuate the ramp efficiently.

- People on the ramp try to escape the life-threatening situation over the staircases, the pole(s), and the container (see Sec. 3.1). This may have been misinterpreted as a 'mob' trying to force its way into the festival area, which needs to be controlled. Pressure relief efforts become effective only very late.

- In absence of separate emergency routes, fences and cordons must be opened to allow an emergency vehicle to pass (see Table 3$).{ }^{6}$ This creates openings for a further inflow of people.

- The overcrowded situation causes dangerous 'crowd turbulence' (see Sec. 3.1). Many people are falling and pile up on top of each other. Emergency forces cannot reach people quickly enough. 21 of them die of suffocation, and more than 500 are injured. ${ }^{11,122}$

- As an unexpectedly large number of people need help, there are not enough emergency forces at the location of the accident. ${ }^{166}$ Therefore, a triage procedure is applied in the tunnel. ${ }^{159}$ As a consequence, many people in critical health conditions do not receive first aid.

\subsection{What might have stopped the feedback and cascading effects}

Overall, one gets the impression that problems occurred on all sides (but we admit that it is easier to identify them afterwards than at the time when decisions must be taken on the basis of often limited and imperfect information). The above analysis shows that things went wrong from the very beginning, and that the situation increasingly got out of control over time. However, we believe that there were also many possibilities to mitigate or overcome problems that contributed to the disaster. Therefore, we will now discuss, how the deadly cascading effect described in the previous subsection might have been stopped or how its size and impact could have been reduced:

- One might have been able to find a better suited area for the organization of the event.

- One could have required higher organizational standards (such as a separation of flow directions).

- The decision to hold the event or not could have been taken earlier. This would have facilitated a better preparation and a better coordination. It would also have reduced the commercial and public pressure in case of deciding against the event. 
- Safety and security concerns could have been taken more seriously. The fact that the responsible police officer quit his job ${ }^{21}$ could have been seen as advance warning sign.

- Superior contingency plans could have been elaborated, in order to be better prepared for the occurrence of various problems. This applies particularly to the handling of the main bottlenecks of the system: the ramp and the access points.

- If the evacuation study had raised serious concerns, this might have been able to stop the approval of the event.

- The various stakeholders could have foreseen larger safety margins and more reserves (also in terms of staff).

- It might have been possible to work out a different flow concept, which separates inand outflows. A circulatory flow organization (where people would come in via the tunnels and both ramps, but leave over the closed-down freeway) would have been interesting to consider.

- Obstacles on the ramp (such as the food stand, fences in the way, and police cars) could have been avoided.

- Efforts could have been made to ensure better communication between the different stakeholders (by reserving [more] priority lines in the mobile phone network) and better communication between the organizers and the crowd (by installing loudspeakers at the ramp and elsewhere). A loudspeaker vehicle could have been moved to the ramp, when it was noticed that no loudspeaker equipment was available on the ramp (around 14:00, see Table 3), or megaphones could have been used to communicate with the crowd.

- When it became clear that people had difficulties to enter the festival area and jams formed on the ramp, one might have been able to move the floats further away from the ramp. Moreover, the side ramp could have been used to avoid the jam on the main ramp.

- The use of more 'pushers' might have been able to increase the outflow from the ramp to the festival area ${ }^{21}$ (but it is not clear how effective this measure would have been, given that the entrance area to the festival ground was quite packed).

- More emergency forces (rescue units) could have been positioned on the ramp and next to it.

- When it was recognized that the crowd management and control did not work as expected, the first police shift might have been extended.

- When the situation became crowded, cordons could have been established at the isolation devices and at the end of the main ramp. The outflow of people could have been redirected (either via the side ramp or via the emergency exits).

- With loudspeakers or megaphones, people on the overcrowded ramp could have been evacuated earlier and in a more effective way, e.g. by organizing an outflow from the ramp to the festival area behind the chain of police cars that were standing on the ramp (see Figure 1). Additionally, a continuous evacuation via the staircase could have been established from 16:15 on (or even from 15:31 on, when people needed to use the slopes to get on the festival area). ${ }^{167}$ Furthermore, the tunnels could have been used to evacuate the ramp, if the flow directions would have been separated.

Given the above alternatives, the crowd disaster might have been avoided in many ways. Already around 13:00 there were first signs that the crowd management concept would not work as planned (see Table 2). Between 14:30 and 15:15 it was noticed that the ramp 
constituted a bottleneck that could get out of control. Around 16:25, people climbing the pole, staircase and container were serious warning signs of a critical situation (see Sec. 3.1). At this time, it would probably have been possible still to evacuate the ramp, if suitable communication tools had been used. However, the ramp emptied only after 17:00.

\section{Lessons to be learned and recommendations}

\subsection{Summary}

One of the noteworthy points of the Love Parade disaster is that most evidence is available online, which allows many scientists and also the broader public to form an opinion. This dramatically changes the situation compared to many previous disasters, where a lot of evidence is of confidential nature, accessible only to a small number of experts. We believe that the new openness of data can have many beneficial effects on society. This study, for example, hopes to make a contribution to a better understanding of crowd disasters and their avoidance in the future. The accessibility of the materials can also serve organizers of mass events, the police and emergency forces to prepare themselves better.

Through the analysis of publicly available materials and videos, we could identify many factors that have contributed to the Love Parade disaster. Our judgement is that the capacity of the area of the mass event already implied various problems, which the organizational concept wanted to overcome by crowd control. However, the delayed start of the event and the unexpected obstruction of the inflow to the festival area from the ramp (i.e. two factors which were probably not anticipated) caused queues that were difficult (or impossible) to manage. Already in the organizational phase, but also in the attempt to manage the flows, many problems came together, and the mutual interaction of these problems made the situation worse. In particular, the cordons that were intended to dissolve the jam at the entrance to the festival area did not yield the expected relief. While they might have worked in case of unidirectional flows, the situation became worse due to the fact that a flow of returning visitors encountered an inflow of arriving people without a separation of the flow directions. From the very beginning, the interaction of many factors resulted in cascading effects, which eventually created a situation that got totally out of control (see Figure 3).

Organizational concepts for mass events are supposed to be robust to the occurrence of single perturbations ('single points of failure'). This in itself, however, does not exclude the possibility that the coincidence or interaction of problems can cause a systemic failure. When certain factors have amplifying effects on other factors (or there are even feedback loops), this can create systemic instabilities. We learn from this that, in order to reach a resilient organization of mass events (and actually any complex system), it is not sufficient to ensure the robustness of each contributing factor. One must also study their interaction effects, to guarantee that the overall organization is resilient to the coincidence of unfavorable factors as much as possible.

Our study also sheds new light on issues that have been controversially discussed. Immediately after the Love Parade disaster, the behavior of the crowd and the staircase were blamed for the fatalities. However, our analysis yields a different interpretation: the Love Parade incident shows the typical features of crowd disasters, such as the existence of bottlenecks (and therefore the accumulation of large numbers of people), organizational problems, communication failures, problematic decisions, coordination problems, and the occurrence of crowd turbulence as a result of high crowd densities. 
It is likely that the staircase encouraged a movement of the crowd towards it, when people were trying to escape from the life-threatening density in the ramp area, but the collective movement seems to have been small (it is not clearly visible in the video recordings). In any case, effective measures (such as an evacuation of the crowd) should have been taken long before critical conditions developed. Given the high density in the ramp area, the occurrence of crowd turbulence or 'crowd quakes' was unavoidable. In this dynamical state of the crowd, the lives of people are in serious danger, as people will fall sooner or later. The triggering of this deadly dynamics does not require a particular reason.

Furthermore, note that the pushing in the crowd at high densities is not necessarily a result of violent behavior, but of the fact that physical forces are transmitted via the bodies of others and adding up. Under such conditions, it is very difficult to keep control over the motion of one's own body, since one is literally moved around by the crowd. The situation in the crowd is difficult also, because no one has an overview of the scene, and the noise level (as well as the overload of the mobile phone network) make communication largely impossible. While the conditions in the crowd were likely to cause a high level of stress, this was a reasonable response to the life-threatening situation. However, a mass panic was most likely not the cause of the Love Parade disaster. The video recordings from the Love Parade do not provide evidence for a stampede of people, while the dangerous phenomenon of crowd turbulence is clearly visible.

Note that crowd disasters during religious pilgrimage in the past recently led to important insights and also to significant improvements of crowd management and control [12-16]. Many of the lessons learned can also be transferred to other mass events in order to improve their safety. The authors propose to consider the following points (besides the official regulations, of course):

- Large mass events should preferably take place in locations where experience with the management of large crowds already exists for a long time. It should at least involve some experts who have participated in the organization of previous mass events and know how to handle critical situations. Local organizing teams should be supported by experienced national or supranational professionals.

- The security concept should be finished, distributed, discussed, and exercised at a pre-specified date well in advance of the event.

- The event must be planned on the basis of the number of expected people, not on the basis of capacity.

- An organizational concept that requires keeping many people out or delays them for hours should be avoided.

- Facilities (e.g. toilets), supply (particularly food and water), as well as entertainment should be ensured also for people on the way to the festival area and for those waiting to enter.

- One should implement ways preventing pressure on decisions that may have impact on the safety and security of people. It should not be possible to ignore qualified minority opinions. Contradictory voices should be documented and seriously addressed.

- Consultants should be encouraged to comment on any critical issues (even beyond the scope of the commissioned analysis).

- An analysis of the expected inflows and outflows (and, hence, number of participants) needs to be performed, considering the possibility of large flow variations. 
A bottleneck analysis is crucial. It must also take into account moving bottlenecks such as floats, but also the operation of police or emergency vehicles. Confluence, turning and intersection points should be determined. In this context, computer simulations with state-of-the art pedestrian software can be useful, but model parameters must be carefully chosen. Note that computer simulations can often help to identify crowded areas, but they are not sufficient to reveal all kinds of organizational challenges.

- Critical points should be removed, and it must be checked, whether the remaining problems can be safely handled by crowd management and control measures also under adverse conditions. Safety margins (such as capacity reserves) should be foreseen[12], and detailed contingency plans should be worked out for likely and unlikely events, and exercised. (Contingency plans serve to reduce the need of improvisation and to ensure a quick and effective response to any occurring problems.) Interaction, cascading and side effects of complicating factors should be analyzed as well. Remaining areas and factors of concern must be continuously monitored (e.g. by video surveillance and special software for real-time analytics). ${ }^{168}$ Sufficient security and emergency forces should always be present to remove or at least mitigate problems early on. Delays in response must be avoided, as they tend to reinforce problems, i.e. quick action is often key to effective counter-measures [59]. To stop possible interaction and cascading effects, suitable decoupling strategies should be implemented.

- Pressure relief and evacuation strategies must be prepared for any potentially critical areas. Evacuation measures must be started before an area becomes over-crowded.

- Intersecting flows should be avoided and different flow directions should be separated (as dense counter-flows are unstable and dangerous [8, 49]). A 'circular' flow organization, preferably with alternative routes, should be considered. ${ }^{169}$ Moreover, space for emergency vehicles and operations should be reserved.

- Fences are not good everywhere. They may turn into obstacles and create dangerous situations. Therefore, the use of fences (or cordons) to stop large numbers of people needs to be carefully considered, as they may be ineffective or deteriorate the situation. In many cases, it is safer to keep people moving (e.g. by re-routing people) rather than stopping them.

- Proper signposting must give visitors orientation everywhere about locations of facilities, ways in and out, and emergency exits.

- Situational awareness and well-functioning communication are crucial. Quick information feedback about the situation in any relevant place and about any relevant factor must be ensured. It is important to have an efficient information flow between the different people and institutions involved (organizers, police, emergency forces, crowd,...).

- In case of problems, the corresponding contingency plan should be applied, and the situation should be continuously (re-)assessed to check for the plausibility of the situational analysis, considering possible alternatives.

- It should be considered to give police and emergency forces more autonomous (local) decision-making power and responsibility, particularly when communication is interrupted or quick action is needed. 
- Communication must work (both, from a technical and an organizational perspective). It is key to detect, avoid, and respond to critical situations. Communication is also crucial for the capacity to reduce undesirable interaction effects and to stop dangerous cascading effects.

- Finally, a safety culture must be actively promoted, reminding everyone that problems can always happen. The motto should be: 'Don't take it easy. Always expect the unexpected!' Preparations for all sorts of surprising situations (including a sudden change of the weather) should be made as much as possible.

\subsection{Some common misconceptions}

As discussed before, our study questions a number of common views about crowd disasters. This concerns the following points:

1 The word 'pushing' suggests that people would relentlessly push forward towards their goal, not caring at all about others.

2 The concept of 'mass panic' sees a stampede as the origin of the crowd disaster, resulting from a contagious mass psychological effect. It also assumes that the crowd behaves unreasonably.

3 The term 'crushing' suggests that the cause of the crowd disaster is an uncontrolled pushing of a crowd towards a bottleneck, which creates densities so high that the bodies of people are crushed.

4 The word 'trampling' suggests that people walk carelessly over others. ${ }^{122}$ Such views tend to blame the crowd for the disaster rather than drawing suitable consequences regarding the organization of mass events, the crowd management and communication. Therefore, recurring disasters may be a consequence of misconceptions about them. In contrast to the above interpretations, our analysis of the crowd disaster in Duisburg suggests the following:

1 It is the 'queuing effect' which causes a denser and denser queue of people over time [47], and a lot of pushing in the crowd happens unintentionally. This is, because physical forces start to add up when the density becomes so high that people start to have body contact. Aggravating factors, which may lead to intentional pushing are (1) long waiting times without food, water, facilities, and entertainment, (2) the absence of understandable, communicated reasons for the delays, and

(3) threatening high-density conditions.

2 The main danger are the laws of physics, not psychology [12, 27, 29, 48]. People do normally not die because they panic - they panic when their life is in danger. ${ }^{170} \mathrm{We}$ do not deny that people get impatient after long waiting times and that some of them also disrespect rules in order to get towards their goal (in particular if these rules do not appear justified to them). However, even under extremely critical conditions, people helped each other and behaved quite rationally. They overcame barriers, used slopes, staircases, poles and the container mainly, when this was necessary to evacuate themselves and reduce the density in the crowd. What might have appeared as an unreasonable crowd forcing its way into the festival area may be better interpreted as a crowd trying to find a way out of the dangerous trap it was in. However, despite a rather rational behavior altogether, some individuals suffered from 'tunnel vision', which is a phenomenon that can occur under conditions of stress. This becomes evident from the fact that those standing around the poles, 
staircase and container, hoping to get out, were not considering alternative emergency routes anymore, even when prompted to them by the police. ${ }^{6,19}$

3 One must distinguish between a 'mass panic', a 'crowd crush' and a 'crowd quake'. In a classical crush, people are moving towards a physical bottleneck and are crushed in front of its narrowest point due to lack of space. ${ }^{171} \mathrm{~A}$ crowd crush might or might not result from a stampede that is caused by mass panic (e.g. as consequence of a bomb threat). ${ }^{172}$ In contrast, in a 'crowd quake', there is typically no systematic flow direction, but people are pushed around by fluctuating forces in the crowd. ${ }^{173}$ In Duisburg, people's lives were endangered not by a stampede that crushed other people, but by a high crowd pressure (defined as density times variability of body movements [48]). An extreme and fluctuating pressure builds up, when the densities become so high that they cause contact forces between bodies to add up. This ultimately implies a sudden onset of 'crowd turbulence'. Under such conditions, the sizes and directions of forces acting on the bodies of visitors move them around in an uncontrolled way, and people have difficulties keeping their balance; when people stumble and fall, this can be the nucleus of a crowd disaster (see next point). ${ }^{139}$ One must distinguish between (active) trampling and being trampled. When trying to avoid the deadly 'domino effect', people may be forced to step on others. ${ }^{140}$ In Duisburg, only a few people were relentlessly 'crawling' or walking over the heads or shoulders of others. This happened around 16:55, when the ultimate inferno of the crowd disaster happened and it was likely that (some) people had already died. Note, however, that many people probably stepped on others who were lying on the ground. Why did they do such a thing? In a dense and shaky crowd, fallen people have difficulties to get up on their feet again. This may cause a 'hole' in the crowd, so that the surrounding people are not anymore counter-balanced: they are pushed from behind, but not anymore from the front. As a consequence, the surrounding people may fall one after another like dominos, causing a pile of people. ${ }^{135,140}$ If they cannot get back on their feet quickly, they are likely to pass out or suffocate, since they cannot breathe anymore under the weight of others piling up on top of them. Therefore, to avoid falling when pushed around by the crowd, people might be forced to step on others. However, under these conditions, they are rather 'walked' than 'walking. That is, while the passive verb 'being trampled' is correct, the active form 'trampling' is misleading.

\subsection{Conclusion and 'natural laws' of crowd behavior}

It is obvious that situations such as the ones described above must be absolutely avoided. This requires the choice of a suitable location and an adequate preparation of the mass event, an appropriate organization and crowd management, and a quick response to early warning signs, for which information and communication play a key role. It is also important to understand that crowd behavior follows certain 'laws of nature', which result from physical, physiological, psychological and social needs of humans such as sufficient space, food, water, and air, toilet facilities, feeling of safety, perceived progress towards the goal, information, communication, entertainment, etc. An insufficient consideration of such factors can promote disasters, particularly if shortcomings accumulate. 
Table 6 This table is intended to help assess the level of criticality of the situation in the crowd and take proactive measures to avoid or at least mitigate crowd disasters

\begin{tabular}{|c|c|c|c|}
\hline & Observation & Assessment & Required action \\
\hline 0 & $\begin{array}{l}\text { Densities are below } \\
2-3 \text { persons per } \\
\text { square meter. }\end{array}$ & $\begin{array}{l}\text { Normal operation at } \\
\text { low risk. }\end{array}$ & $\begin{array}{l}\text { Regularly verify normal operation, watch out for } \\
\text { perturbations. Make sure that the flow does not } \\
\text { exceed the safe value of } 82 \text { persons per minute and } \\
\text { meter. }\end{array}$ \\
\hline 1 & $\begin{array}{l}\text { People accumulate. } \\
\text { Certain areas become } \\
\text { progressively more } \\
\text { crowded. }\end{array}$ & $\begin{array}{l}\text { People slow down } \\
\text { due to a bottleneck } \\
\text { or stop for some } \\
\text { reason. }\end{array}$ & $\begin{array}{l}\text { Limit inflows to ensure that the expected extent of } \\
\text { accumulation will not be exceeded. Gather } \\
\text { information and determine the reasons for the } \\
\text { accumulation. Prepare possible counter-measures. } \\
\text { Move enough security to the respective area. Inform } \\
\text { the responsible police and emergency units. }\end{array}$ \\
\hline 2 & $\begin{array}{l}\text { Jams of people are } \\
\text { forming and growing. }\end{array}$ & $\begin{array}{l}\text { Insufficient outflows } \\
\text { may cause serious } \\
\text { problems over time } \\
\text { (such as high } \\
\text { densities), particularly } \\
\text { in constraint spaces. }\end{array}$ & $\begin{array}{l}\text { Communicate with the crowd. Promptly take } \\
\text { appropriate flow reduction measures such as } \\
\text { re-directing people. (Keep in mind that stopping } \\
\text { people causes a growing pressure in the crowd and } \\
\text { impatience.) Move police and emergency units } \\
\text { towards the crowded area(s) in case help will be } \\
\text { needed. }\end{array}$ \\
\hline 3 & $\begin{array}{l}\text { Stop-and-go waves } \\
\text { occur (this happens } \\
\text { only in dense moving } \\
\text { crowds). People are } \\
\text { pushed. }\end{array}$ & $\begin{array}{l}\text { The continuous flow } \\
\text { has broken down. } \\
\text { The outflow capacity } \\
\text { is considerably } \\
\text { reduced. The } \\
\text { situation may } \\
\text { escalate quickly. }\end{array}$ & $\begin{array}{l}\text { Take suitable counter-measures. Pressure relief } \\
\text { strategies (such as opening emergency routes and } \\
\text { re-routing inflows) should be taken and people } \\
\text { informed about them. Before, any obstacles (such as } \\
\text { fences) in the way must be removed. A sufficient } \\
\text { number of emergency units and police must be in } \\
\text { the critical area and ready take over control in } \\
\text { interaction with the crowd management. }\end{array}$ \\
\hline 4 & $\begin{array}{l}\text { People cannot move } \\
\text { freely and are } \\
\text { squeezed between } \\
\text { others. People are } \\
\text { pushed around. }\end{array}$ & $\begin{array}{l}\text { A critical density has } \\
\text { built up in the crowd. } \\
\text { Injuries can easily } \\
\text { happen. }\end{array}$ & $\begin{array}{l}\text { Police should take over control in close consultation } \\
\text { with the crowd management. Appropriate } \\
\text { contingency plans must be applied. Evacuation is } \\
\text { strongly advised. Communication with the crowd is } \\
\text { crucial. Emergency forces must be in the most } \\
\text { crowded areas, in order to provide first aid whenever } \\
\text { needed. }\end{array}$ \\
\hline 5 & $\begin{array}{l}\text { People disrespect } \\
\text { fences or try to get } \\
\text { out of the area. }\end{array}$ & $\begin{array}{l}\text { The situation is critical } \\
\text { and likely to get out } \\
\text { of control. }\end{array}$ & $\begin{array}{l}\text { Communicate with the crowd and evacuate it. } \\
\text { Provide help and first aid. Inform hospitals and } \\
\text { additional emergency units about the possibility that } \\
\text { the situation may get out of control. }\end{array}$ \\
\hline 6 & $\begin{array}{l}\text { Crowd turbulence } \\
\text { occurs. People } \\
\text { scream or shout for } \\
\text { help. }\end{array}$ & $\begin{array}{l}\text { Injuries and fatalities } \\
\text { are likely. A crowd } \\
\text { disaster can happen } \\
\text { any time. }\end{array}$ & $\begin{array}{l}\text { Calm down the crowd and guide it. Continue to } \\
\text { evacuate people. Watch out for the areas with the } \\
\text { highest densities and largest crowd movements, to } \\
\text { ensure support and first aid. Additional emergency } \\
\text { vehicles must be called to ensure sufficient } \\
\text { manpower, and hospitals must be informed about } \\
\text { likely (and potentially many) injuries. }\end{array}$ \\
\hline 7 & $\begin{array}{l}\text { People are falling to } \\
\text { the ground. People } \\
\text { raise arms into the air. }\end{array}$ & $\begin{array}{l}\text { People are in big } \\
\text { trouble. Many injuries } \\
\text { are to be expected. A } \\
\text { crowd disaster is } \\
\text { (most likely) } \\
\text { happening. }\end{array}$ & $\begin{array}{l}\text { Immediate help and first aid are needed, probably for } \\
\text { many people. Hospitals must be prepared to shift } \\
\text { from routine to large-scale emergency operation. }\end{array}$ \\
\hline 8 & $\begin{array}{l}\text { People crawl over } \\
\text { others. }\end{array}$ & $\begin{array}{l}\text { A crowd disaster has } \\
\text { probably happened. }\end{array}$ & Apply rules for a state of serious emergency. \\
\hline
\end{tabular}

Note that at each of these levels, one must already take first preparations for the next one or two (as the situation may change quickly) and communicate the possible scenarios and their implications to all relevant stakeholders. The goal is to de-escalate the situation and get back to lower levels of criticality. 


\subsection{Advance warning signs of crowd disasters}

To improve the situational awareness of crowd managers, police and emergency forces, Table 6 lists a number of successive warning signs of increasingly critical crowd conditions.

\subsection{Emerging relevance of citizen science and further conclusions}

In the subsection above, we have presented science-based suggestions for the avoidance of crowd disasters and an organizational response to critical situations. Deriving these conclusions largely profited from the huge amounts of materials that volunteers have provided, collected, synchronized, and ordered (according to time, locations, content, etc.). This is, where 'citizen science' can play an important role. The documentation we have seen from volunteers appears to be more transparent and complete than the information provided by public institutions, and it is better accessible than news from many public and private media (where we often faced the issue that materials could not be retrieved anymore, at least not under the original links).

Also, scientific institutions would not have had enough resources to do all the documentation work that was performed by these volunteers. However, the collected materials are so voluminous that one can hardly see the wood for the trees. Therefore, citizen science can largely benefit from an interaction with academic experts. Specialized knowledge is needed to distinguish more relevant from less relevant factors, to interpret empirical evidence, and distinguish more likely from less likely explanations. Besides providing this knowledge, our work also highlights the general and systemic nature of crowd disasters, and it reveals the instabilities (amplification effects) and cascading effects leading to them.

The systemic nature of many crowd disasters makes their legal handling very difficult, since it is hard to determine the fraction of responsibility that different people and institutions had. However, without a proper response to such systemic failures, people are losing their trust in public institutions, and this undermines their legitimacy. ${ }^{174}$

Crowd disasters are not the only systemic risk, resulting from interactions and institutional settings that are not suitably designed. The financial crisis is another example, ${ }^{161,162}$ for which nobody seems to be willing to take responsibility. This is mainly, because the individual contributions to it cannot be well quantified. Also human history is full of examples of humanitarian disasters, which happened because nobody felt sufficiently responsible for them. The authors are convinced that the division of responsibility itself is the problem, and that this calls for political and regulatory attention. Scientists could perhaps make a major contribution to the cultural heritage of humanity, if they managed to find new ways to address this fundamental problem [60].

Competing interests

The authors declare that they have no competing interests.

$\mathrm{DH}$ lead the study and assessed the findings. Both authors evaluated the publicly available movies, wrote, read, and approved the manuscript. PM developed the web application for collecting, time-ordering and geo-tagging videos, and produced the figures according to DH's instructions. 


\section{Acknowledgements}

We would like to thank everyone who has publicly provided materials documenting the Love Parade, and those who have been carefully synchronizing, ordering, analyzing, and describing these materials in hundreds of hours of work. This work has ultimately contributed to the creation of a public good, namely better public safety at future mass events, as it allows many people to learn from mistakes made in the past.

\section{Endnotes}

The following complementary webpage with time-ordered, geo-located videos been set up for this paper: http://loveparadevideos.heroku.com/. Note: Web materials (URL links) were last accessed during March and April 2012.

2 Government of Canada, Emergency preparedness guidelines for mass, crowd-intensive events, see http://orise.orau.gov/csepp/documents/planning/evacuation-documents/guidance-documents/ canada-crowdevents.pdf (1994).

3 Richtlinie für Mikroskopische Entfluchtungsanalysen (in German) The RiMEA Project, see http://www.rimea.de/downloads.html (2008).

4 Musterversammlungsstättenverordnung [German Safety Regulations for Public Events], see http://www.is-argebau.de/Dokumente/4231214.pdf and http://de.wikipedia.org/wiki/Versammlungsstättenverordnung (2008).

5 Still, K., Crowd Dynamics, Ph.D. thesis, University of Warwick, Warwick (2000); see http://www.safercrowds.com/PhD-Chapter-2.html for the quote given in our manuscript.

6 Polizeipräsidium Essen, Vorläufiger Abschlussbericht from 31. Oktober 2010 zur Nachbereitung des polizeilichen Einsatzes der Veranstaltung 'Loveparade' am 24.07.2010 in Duisburg [Police Report], see http://www.mik.nrw.de/fileadmin/user_upload/Redakteure/Dokumente/Themen_und_Aufgaben/ Schutz_und_Sicherheit/110601_vorlaeufiger-abschlussbericht.pdf.

7 Final report of the city of Duisburg, see http://www.duisburg.de/ratsinformationssystem/bi/vo0050.php?_kvonr=200561 10\&voselect=20049862.

8 For a Google Earth photograph of the Love Parade festival area in Duisburg and its surrounding, see http://www.earth-dots.de/massenpanik-auf-der-love-parade-99843.html. For an aerial photograph taken on the day of the event see http://www1.wdr.de/themen/archiv/sp_loveparade/loveparade112.html.

9360 degree representation of the site of the event: http://www1.wdr.de/themen/archiv/sp_loveparade/loveparade150.html; a Google Streetmap version can be found here: $\mathrm{http}: / / \mathrm{g} . \mathrm{co} / \mathrm{maps} / 65 \mathrm{r} 7 \mathrm{j}$.

10 YouTube channel with videos of the Love Parade in Duisburg, see http://www.youtube.com/user/LoveparadeDuisburg?feature=watch.

11 Wikipedia article on the Love Parade Disaster: http://en.wikipedia.org/wiki/Love_Parade_stampede.

12 Wikipedia article on the Love Parade and its history: http://en.wikipedia.org/wiki/Love_Parade.

13 Wikipedia map associated with German Wikipedia article: http://en.wikipedia.org/wiki/File:\%C3\%9Cbersichtskarte_Loveparade_Duisburg_2010.jpg.

14 Loveparade 2010 Duisburg planning documents, 2007-2010, see http://wikileaks.org/wiki/Loveparade_2010_Duisburg_planning_documents,_2007-2010.

15 Expert opinion on the areas of responsibility of the organizer, city of Duisburg, and police at the Love Parade 2010, see http://www.mik.nrw.de/fileadmin/user_upload/Redakteure/Dokumente/Themen_und_Aufgaben/ Schutz_und_Sicherheit/100901gutachten_sfe.pdf.

16 http://loveparade2010doku.wordpress.com/links/.

17 Event Log of the City of Duisburg, http://loveparade2010doku.files.wordpress.com/2010/10/10-1405_2_anlage_621.pdf.

18 Entfluchtungsanalyse Love Parade 2010 [Evacuation analysis Love Parade 2010], see http://docunews.org/go/2010_07_13-traffgo-ht-entfluchtungsanalyse-loveparade-2010-49/, Entfluchtungsanalyse Loveparade 2010, Nachtrag [Supplement], see Anlage 30 [attachment no. 30] at https://www.duisburg.de/ratsinformationssystem/bi/vo0050.php?_kvonr=20056110\&voselect=20049862.

19 Documentation of the events during the Love Parade 2010 in Duisburg, see http://loveparade2010doku.wordpress.com.

20 Synchronized video collection, with information regarding location and content, see http://loveparade2010doku.wordpress.com/2010/07/31/loveparade-ungluck-videos-verknupfen-zeitstrahl/ . The synchronization procedure is described in http://loveparade2010doku.files.wordpress.com/2012/02/lopa_zeitstrahl-verknuepfungen_v120218.pdf.

21 A. Brandt, G. Bönisch, J. Dahlkamp, and S. Röbel, Schwarzer Samstag, Der Spiegel 20/2011, pp.59-69, see http://www.spiegel.de/spiegel/print/d-78522270.html.

22 Tagesschau Love Parade Dossier, see http://www.tagesschau.de/inland/dossierloveparade100.html.

23 WDR Love Parade Dossier, see http://www.wdr.de/mediathek/html/regional/uebersicht/katastrophe-loveparade.xml.

24 Spiegel TV documentation on the Love Parade, see http://www.spiegel.de/video/video-1077726.html.

25 Spiegel TV documentation on the Love Parade: http://www.youtube.com/watch?v=OpdOrZVsspQ, http://www.youtube.com/watch?v=DTbJ_vbT8Cw, http://www.youtube.com/watch?v=S9ILNAv0J1A, http://www.youtube.com/watch?v=FHD8aqsCr9U. 
RTL II video documentation '100 Tage' [100 days later] on the Love Parade: 1/15 http://www.youtube.com/watch?v=fy1NDX_nA3M, 2/15 http://www.youtube.com/watch?v=38iqVvS_Ljs,

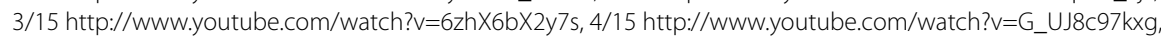
5/15 http://www.youtube.com/watch?v=2ZVZlrhXeBw, 6/15 http://www.youtube.com/watch?v=T5qNYmpD5mk, 7/15 http://www.youtube.com/watch?v=KKqXMvAWprc, 8/15 http://www.youtube.com/watch?v=Sgl2aKofkLk, 9/15 http://www.youtube.com/watch?v=0y00qe3PPsc, 10/15 http://www.youtube.com/watch?v=4azc7lPhVnU, 11/15 http://www.youtube.com/watch?v=HRC7S4qlvjs, 12/15 http://www.youtube.com/watch?v=cnr7S22_BM8, 13/15 http://www.youtube.com/watch?v=_RZgYhzekjs, 14/15 http://www.youtube.com/watch?v=AusbCbphWAo, 15/15 http://www.youtube.com/watch?v=mVYTlhkcKDY.

27 Video documentation of the organizers: http://www.youtube.com/watch?v=8y73-71FBNE (in English) http://www.youtube.com/watch?v=tAomrwggo2s (in German)

28 Synchronized multi-perspective video, see http://www.youtube.com/watch?v=up95bUU3LOM.

29 Overview videos cut from many videos of visitors, see: http://www.youtube.com/watch?v=V9cbqu5sEE0 http://www.youtube.com/watch?v=cDJaAvFol7s http://www.youtube.com/watch?v=sBE79UoxCF4 http://www.youtube.com/watch?v=qJscpcZC $45 \mathrm{~s}$ http://www.youtube.com/watch?v=vooMCrcOXGs http://www.youtube.com/watch?v=pOx_VHJd6G4.

30 Video documentation by 'LoveparadeDuisburg': Part 1: http://www.youtube.com/watch?v=BRUIHnvJl-Q Part 2: http://www.youtube.com/watch?v=VDOIXcobbJM Part 3: http://www.youtube.com/watch?v=y_agoPIP_dA Part 4: http://www.youtube.com/watch?v=pfxdSZg9KWk.

31 Critical summary videos, see http://www.youtube.com/watch?v=NxGSrPALytM and http://www.youtube.com/watch?v=up95bUU3LOM.

32 Video illustrating the events with comments on a satellite image, see http://www.youtube.com/watch?v=TCOYgi7AMfM.

33 Incomplete collection of surveillance videos of the organizer of the Love Parade, see http://loveparade2010doku.wordpress.com/2010/08/30/lopavent-veroffentlicht-originalvideos-von-7-der-16uberwachungskameras-der-loveparade-2010/\#downloads. Camera 14 and 15 covered the tunnel in the West, camera 16 the one in the East. Camera 13 provided a view over the ramp. Camera 12 shows the upper part of the ramp and the part where it enters the festival area. Camera 4 shows the view from the stage on the festival area, sometimes pointing approximately towards the ramp. The floats and the surrounding people are shown by cameras 4, 5 and 12. An overview of 6 surveillance cameras it given at: 15:30-15:40: http://www.youtube.com/watch?v=P18RLNIWgKQ 15:40-16:00: http://www.youtube.com/watch?v=YbFoNTyBmpl 16:00-16:20: http://www.youtube.com/watch?v=cfQVqitwlAQ 16:20-16:40: http://www.youtube.com/watch?v=ignCf7-BnBg

34 Time line: http://loveparade2010doku.wordpress.com/2010/07/28/loveparade-2010-zeitablauf-sperrungen-unddurchlassungen/, http://blog.odem.org/2010/07/ablauf-tragoedie.html.

35 Collection of videos, time-ordered, with approximate geo-location of filming person: http://loveparadevideos.heroku.com/.

36 Before 16:07:30 CURUBA300 http://www.youtube.com/watch?v=Eaq2DPmafyl 16:15:52 Todesparade2010 1/10 http://www.youtube.com/watch?v=kVpkclRCXaQ 16:16:35 trampelklette $1 \mathrm{http}: / /$ www.youtube.com/watch?v=KaDoWMAZYyo 16:22:54 xetzxetzxetz 16:25 http://www.youtube.com/watch?v=P3jL17JOA8U 16:23:45 thaido http://www.youtube.com/watch?v=6SXgp3VIM88 16:24:12 Todesparade2010 3/10 http://www.youtube.com/watch?v=_PQqBePT6ig 16:24:38 GermanTranceMusic 1 http://www.youtube.com/watch?v=yNcIINGQkgk 16:24:48 pizzamanne 2 [from 16:24] http://www.youtube.com/watch?v=8aQuTaMbS38 16:24:54 trampelklette $2 \mathrm{http}: / /$ www.youtube.com/watch?v=MSGJW1uJMS0 16:25:29 xetzxetzxetz 16:27 http://www.youtube.com/watch?v=MvlzywaFnmc 16:26:07 Todesparade2010 4/10 http://www.youtube.com/watch?v=so6-7Ezeo3U 16:26:20 Letroen http://www.youtube.com/watch?v=PMld0jhO7Jk 16:28:24 pizzamanne http://www.youtube.com/watch?v=8aQuTaMbS38 16:29:01 dirkbvb74-1 http://www.youtube.com/watch?v=YmQR6kgwSXA 16:29:12 coolwojtek 1 http://www.youtube.com/watch?v=wsOylBCMEXM 16:29:40 funka84 http://www.youtube.com/watch?v=t3nDQti-zDY 16:29:44 Todesparade2010 6/10 http://www.youtube.com/watch?v=WTiQ131QejE 16:30:33 pizzamanne 2 [from 16:30] (starting at 2:15) http://www.youtube.com/watch?v=8aQuTaMbS38 16:31:21 TheHubschrauber92 http://www.youtube.com/watch?v=cPkemW3ixC4 16:31:59 rheinhousen 2 http://www.youtube.com/watch?v=UBkilEAyK80 16:32:10 dreamshockerPro http://www.youtube.com/watch?v=adZ6RaK8C-E 16:33:11 Habanos2009 http://www.youtube.com/watch?v=EoX1rPefuul 16:33:55 joelooo1 $1 \mathrm{http}: / / w w w . y o u t u b e . c o m / w a t c h ? v=r V v U 11$ LVEwQ 16:34:49 joelooo 2 http://www.youtube.com/watch?v=Mw4W6z_wWcM 16:34:51 xfugox http://www.youtube.com/watch?v=arncFs1DU0k 
16:35:11 pizzamanne 2 [from 16:35] http://www.youtube.com/watch?v=8aQuTaMbS38 16:35:19 Deepkisses [from 16:23] http://www.youtube.com/watch?v=3XFTVWUN8nw 16:35:32 dirkbvb74-2 http://www.youtube.com/watch?v=r1 toPUusRGU 16:36:09 MarkusLedwig http://www.youtube.com/watch?v=h3ik6n2BPa8 16:37:06 KoOrn http://www.youtube.com/watch?v=m597wnEMUTo 16:37:11 xetxetzxetz 16:38 http://www.youtube.com/watch?v=mo97xHkHh3w 16:37:36 Cenobite1988 http://www.youtube.com/watch?v=UqV3Nx0MFh4 16:37:44 real02 3/3 http://www.myvideo.de/watch/7673480/Massenpanik_Loveparade2010_3_3 16:37:57 GSayMusic http://www.youtube.com/watch?v=kUEB4OcsoRM (removed) 16:37:58 Klabauter0815 http://www.youtube.com/watch?v=B1 usiOJRWDU (removed) 16:38:16 Goonies11000 http://www.youtube.com/watch?v=6dReLGi1 Inc 16:38:23 pizzamanne 2 [from 16:38] http://www.youtube.com/watch?v=8aQuTaMbS38 16:38:28 aggrostar69 http://www.youtube.com/watch? $\mathrm{v}=-2$-2onoJLq2-8 16:38:50 dirkbvb74-3 http://www.youtube.com/watch?v=UWXXDEZ40Kg 16:39:01 Deepkisses $2 \mathrm{http}: / /$ www.youtube.com/watch?v=3XFTVWUN8nw 16:39:20 SpaceCommander77 http://www.youtube.com/watch?v=gLdhwP4_IXM 16:39:26 FrEaKyLaDiiiEs http://www.youtube.com/watch?v=d1 la2QTDBPU 16:39:38 GoofyMcPott http://www.youtube.com/watch?v=00jNklbvxA8 16:41:27 pizzamanne 3 [from 16:41] http://www.youtube.com/watch?v=9DvH1BYFVCQ 16:41:40 SKAKnabe http://www.youtube.com/watch?v=prXmQBf27WI (removed).

37 Collection of synchronized videos by 'pizzamanne' (potentially incorrect time stamp on videos in brackets): 1017 - ca. 15:38 (15:38 / 15:38:38) - http://www.youtube.com/watch?v=OGd1N6_hm1 k 1019 - ca. 15:58 (15:58 / 15:58) - http://www.youtube.com/watch?v=vdJzV26tL78 1022 - ca. 16:07 (16:07 / 16:07:12) - http://www.youtube.com/watch?v=2_LfccdiSNo 1024 - ca. 16:08 (16:08; 16:08:49) - http://www.youtube.com/watch?v=-4f8AMEstkM 1029 - ca. 16:11 (16:11 / 16:11:53) - http://www.youtube.com/watch?v=_Zsmr9CelDY 1033 - ca. 16:15 (16:15 / 16:15:36) - http://www.youtube.com/watch?v=_gJP2QVbwVs 1034 - ca. 16:17 (16:17 / 16:17) - http://www.youtube.com/watch?v=pweaCIXTs5U 1035 - ca. 16:18 (16:18 / 16:18) - http://www.youtube.com/watch?v=f00Mx8MY6y8 1037 - 16:22:55 (16:22 / 16:22:54) - http://www.youtube.com/watch?v=Lkc7zgPv8y0 1038 - 16:24:49 (16:24 / 16:24:48) - http://www.youtube.com/watch?v=9wpVvSWa4_8 1039 - 16:28:24 (16:28 / 16:28:24) - http://www.youtube.com/watch?v=NmEcLa4OfvU 1040 - 16:30:33 (16:30 / 16:30:34) - http://www.youtube.com/watch?v=Ra_j4kTOqqE 1041 - 16:35:11 (16:35 / 16:35:12) - http://www.youtube.com/watch?v=AYj|XhPcF4s 1043 - ca. 16:37 (16:37 / 16:37) - http://www.youtube.com/watch?v=Od-DGsPlues 1044 - 16:38:22 (? / 16:38:24) - http://www.youtube.com/watch?v=Y3qlzW-B9OM 1054 - 16:59:23 (16:59/ 16:59:35) - http://www.youtube.com/watch?v=Uk9BXDdGJoQ 1055 - ca. 17:04:43 (?) (17:04 / 17:04:43) - http://www.youtube.com/watch?v=qUBjVtjwl30 1056 - ca. 17:06 (17:06 / 17:06) - Schnipsel von 1 Sek. - http://www.youtube.com/watch?v=oCyzQ4NgVBU 1057 - 17:08:40 (17:08 / 17:08:50) - http://www.youtube.com/watch?v=iJ4NdwXa0Os 1058 - ca. 17:23 (17:23 / 17:23) - http://www.youtube.com/watch?v=qtyC1YvwbEc 1065 - ca. 20:38 (20:38 / 20:38:35) - http://www.youtube.com/watch?v=UEFnUi5w7gs 1067 - ca. 20:47 (20:47 / 20:46:55) - http://www.youtube.com/watch?v=ZsUHVV_k3r0 1068 - ca. 20:49 (20:49 / 20:49:31) - http://www.youtube.com/watch?v=3UYacod0w6g.

38 Collection of synchronized multi-view videos, by 'pizzamanne': Part 1 (15:20-16:25): http://www.youtube.com/watch?v=V9cbqu5sEE0 Part 2 (16:25-16:34): http://www.youtube.com/watch?v=cDJaAvF0l7s Part 3 (16:34-16:44): http://www.youtube.com/watch?v=sBE79UoxCF4 Part 4 (16:44-16:54): http://www.youtube.com/watch?v=qJscpcZC45s Part 5 (16:54-17:05): http://www.youtube.com/watch?v=vooMCrcOXGs Part 6 (17:05-17:20): http://www.youtube.com/watch?v=pOx_VHJd6G4

39 Video collection of 'kaydee271':

1/8 - ca. 15:25 - http://www.youtube.com/watch?v=2fT7qKC8QOw 2/8 - ca. 15:35 - http://www.youtube.com/watch?v=rrpYKGNIhdw 3/8 - 17:03:34 - http://www.youtube.com/watch?v=loxPIvrFCNg 4/8 - 17:05:14 - http://www.youtube.com/watch?v=t3_3UIZS3dw 5/8 - 17:09:41 - http://www.youtube.com/watch?v=Kc8wEMiOxoo 6/8 - 17:11:19 - http://www.youtube.com/watch?v=gN4NNmxtRU4 7/8 - 17:12:08 - http://www.youtube.com/watch?v=JfaLr_Y4U18 8/8 - 17:15:15 - http://www.youtube.com/watch?v=FYXQLgd_VA8.

40 Video collection of 'tr1 nd' ('Backtony'): http://www.youtube.com/watch?v=vAxOeGUCZNI.

41 Video collection of 'real02':

3/3 - 16:37:44 - http://www.youtube.com/watch?v=IdtR4Ks_n6l, also at http://www.myvideo.de/watch/7673480/Massenpanik_Loveparade2010_3_3 1/3 - 16:58:19 - http://www.youtube.com/watch?v=dP-5VOCU30U, also at http://www.myvideo.de/watch/7673149/Massenpanik_Loveparade2010_1_3, 2/3 - 17:05:52 - http://www.youtube.com/watch?v=HvXwrbCjgf4, also at http://www.myvideo.de/watch/7673325/Massenpanik_Loveparade2010_2_3.

42 Video collection of 'hitower78': 1 - 16:36:17 (16:08:43 / 16:36:21 [16:37:27]) - http://www.youtube.com/watch?v=0ioEPdfvZdw 
2 - 16:50:23 (16:22:49 / 16:50:27) - http://www.youtube.com/watch?v=u2r1AFSuHNI

3 - 16:52:33 (16:24:59 / 16:52:37) - http://www.youtube.com/watch?v=IEtFZVOjsK4.

43 Video collection of 'Todesparade2010':

1/10 - 16:15:52 (16:16) http://www.youtube.com/watch?v=kVpkcIRCXaQ 2/10 - ca. 16:22 (16:23) http://www.youtube.com/watch?v=|Fxyl9OaqHk 3/10 - 16:24:12 (16:25) http://www.youtube.com/watch?v=_PQqBePT6ig 4/10 - 16:26:07 (16:27) http://www.youtube.com/watch?v=so6-7Ezeo3U 5/10 - ca. 16:29 (16:30) http://www.youtube.com/watch?v=VohMiM54wpA 6/10 - 16:29:44 (16:31) http://www.youtube.com/watch?v=WTiQ131 QejE 7/10 - ca. 16:31 (16:32) http://www.youtube.com/watch?v=qnZGcnWyJOM 8/10 - ca. 16:33 (16:34) http://www.youtube.com/watch?v=3cVyb3W-GAM 9/10 - ca. 16:52 (16:53) http://www.youtube.com/watch?v=hPZiHkZQH98 10/10 - ca. 16:53 (16:54) http://www.youtube.com/watch?v=2PI1dVP8bA4.

44 Video collection of 'goonies 11000':

1 - 16:38:15 - http://www.youtube.com/watch?v=6dReLGi1 lnc

2 - 16:55:51 - http://www.youtube.com/watch?v=L9wfsupvD24

3 - 16:59:41 - http://www.youtube.com/watch?v=rzz5geLWPV4

4 - 17:18:35 - http://www.youtube.com/watch?v=qbQr5yAjqxs.

45 Video collection of 'coolwojtek':

1 - 16:29:12 (16:28:42) - http://www.youtube.com/watch?v=wsOylBCMExM

2 - 16:44:44 (16:44:14) - http://www.youtube.com/watch?v=8aTXT3ht8VU

3 - 16:48:34 (16:48:04) - http://www.youtube.com/watch?v=1|HLIn78650

4 - 16:51:02 (16:50:32) - http://www.youtube.com/watch?v=XKo3rb5R_Dc

5 - 16:54:36 (15:53:36) - http://www.youtube.com/watch?v=xxd_KlaCiNY.

46 Video collection of 'mbreezer':

Summary - http://www.youtube.com/watch?v=OfQjXi3J3ns

0 - 16:38:36 - http://www.youtube.com/watch?v=5uio5rSv520

$1-16: 47: 31$ - http://www.youtube.com/watch?v=rgvG2Pp7yfc

$2-16: 51: 41$ - http://www.youtube.com/watch?v=offd928JY6k

3 - 16:53:07 - http://www.youtube.com/watch?v=3aodLRaPu0E

4 - 16:53:50 - http://www.youtube.com/watch?v=u8N3ZcqOgfU

$5-16: 55: 05-$ http://www.youtube.com/watch?v=JdbIWBmaM4Q

6 - 17:00:30 - http://www.youtube.com/watch?v=VTF0v-WY934

7 - 17:02:47 - http://www.youtube.com/watch?v=V-WKhjRMcRM

$8-17: 03: 11-$ http://www.youtube.com/watch?v=s2ywRwxfHbo

9- 17:05:48 - http://www.youtube.com/watch?v=52KPyHrqkwY

47 Video collection of 'The1 art 1 of 1 hell':

1 - 16:59:05 (16-58-09) - http://www.youtube.com/watch?v=YxIZwvvhpp8

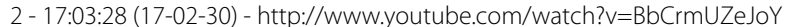

3 - 17:05:38 (17-03-33) - http://www.youtube.com/watch?v=NLC3vyp0b9U

4 - 17:07:30 (17-05-42) - http://www.youtube.com/watch?v=QcAVAYDolKc

5 - 17:08:48 (17-07-34) - http://www.youtube.com/watch?v=-iCA6g984aY

6 - 17:09:52 (17-08-51) - http://www.youtube.com/watch?v=LXLuogNDJ-A

$7-17: 11: 26$ (17-09-31) - http://www.youtube.com/watch?v=-7WDbM4EonY

8 - 17:12:28 (17-11-30) - http://www.youtube.com/watch?v=zCRGtjcbyw8

9 - 17:13:47 (17-12-32) - http://www.youtube.com/watch?v=gEa9_k-Th7U

10 - 17:14:50 (17-13-51) - http://www.youtube.com/watch?v=_CiEkTPk9BQ.

48 Video collection of 'rkjorge 70 ':

1 - 17:10:44 - http://www.youtube.com/watch?v=Nb0m_nOKGms

2- 17:13:26 - http://www.youtube.com/watch?v=qQbto4MNaOU

3 - 17:19:41 - http://www.youtube.com/watch?v=WR56iEfBQoo.

49 Pictures of the Love Parade in Berlin, see: http://www.skyscrapercity.com/showpost.php?s=dabeccde05e177be86cfa 1009c0e245e\&p=60946437\& postcount $=44$.

50 See http://de.wikipedia.org/wiki/Weltjugendtag_2005, http://en.wikipedia.org/wiki/Marienfeld, http://commons.wikimedia.org/wiki/Category:Marienfeld_\%28World_Youth_Day\%29?uselang=de.

52 For a photograph of the triangular fences see http://loveparade2010doku.files.wordpress.com/2010/07/googlemaps_bauzaeune_rampe.jpg.

53 Foodstand on the ramp, see http://www.youtube.com/watch?v=BhFoNb_IsO4 and http://www.youtube.com/watch?v=dP-5VOCU30U.

54 Obstacles on the ramp and change of police shifts, see http://www.youtube.com/watch?v=sBElur_IBuw, http://www.youtube.com/watch?v=AN_8zwycDYO

55 Visitor forecast of Lopavent from July 8, 2010, see http://loveparade2010doku.files.wordpress.com/2011/08/bewegungsmodell.jpg, http://loveparade2010doku.files.wordpress.com/2011/08/bewegungsmodell.pdf, and the endnote ${ }^{14}$ 
56 The operation of the access points (isolating devices) can been seen in this video: http://www.youtube.com/watch?v=DTbJ_vbT8Cw The video also mentions communication problems and that the emergency units were not prepared for such a disaster.

57 Aerial photographs of the Love Parade in Duisburg, see http://www.aerophoto.de/album.php?id=20100724\%2018\%201\%20Loveparade_2010\&language=0.

58 Video of the crowd on the festival area, see http://www.youtube.com/watch? $v=b d 81$ KlpuVc8 and the recordings of surveillance camera 4.33

59 G. K. Still, Duisburg - 24th July 2010, Love Parade Incident, see http://www.derwesten-recherche.org/wp-content/uploads/2012/02/Still-Gutachten.pdf.

60 Interview with the organizer of the Love Parade, see http://www.youtube.com/watch?v=wslvv6GQVkg

61 Estimated inflows and outflows based on videos of surveillance camera 13 are provided at http://loveparade2010doku.wordpress.com/2011/08/06/bewegungsmodell/.

62 Surveillance videos of the ramp can be seen at: 14:00-14:20: http://www.youtube.com/watch?v=ZJ28eiBoS0g 14:20-14:40: http://www.youtube.com/watch?v=FMgs_y8_Ftg 14:40-15:00: http://www.youtube.com/watch?v=wx2GlfGCHo4 15:00-15:20: http://www.youtube.com/watch?v=IzrzMU8L3TY 15:20-15:40: http://www.youtube.com/watch?v=YbdDm/YYb8c 15:40-16:00: http://www.youtube.com/watch?v=Xgt9fh841P4 16:00-16:20: http://www.youtube.com/watch?v=CIhGnrR6Utc 16:20-16:40: http://www.youtube.com/watch?v=QpzISdBE3dA.

63 Change in police shift, see http://www.youtube.com/watch?v=YGPrzaxsD7l\&list=UUlmsa1MvDRyVXsvCld8LMzQ\&index=2\&feature=plcp.

64 Police cordon in the Western tunnel, see http://www.youtube.com/watch?v=B-YX7tvcVYw, http://www.youtube.com/watch?v=e_exvp1NMjw, and http://www.youtube.com/watch?v=jXcTJfmS7RQ

65 Formation of police cordon 3 in the middle of the ramp, see http://www.youtube.com/watch?v=W5BOam3eGXA and http://www.youtube.com/watch?v=joBsBYcGVsw.

66 Queues are forming on both sides of the narrowing created by triangular fences on the ramp, when police forces start to control in- and outflows, thereby creating a bottleneck, see http://www.youtube.com/watch?v=CIhGnrR6Utc, http://www.youtube.com/watch?v=W5BOam3eGXA, and http://www.youtube.com/watch?v=joBsBYcGVsw.

67 The second police cordon in the Eastern tunnel opens up, see http://www.youtube.com/watch?v=SGx1hsOmm_M and http://www.youtube.com/watch?v=CIhGnrR6Utc.

68 First visitors are entering the festival area via the narrow staircase, see http://www.youtube.com/watch?v=KaDoWMAZYyo and http://www.youtube.com/watch?v=-CEnjxQBmf4

69 Security people prevent a flow of people on the staircase, see http://www.youtube.com/watch?v=IFxyl9OaqHk.

70 The first police cordon in the Western tunnel opens up, see http://www.youtube.com/watch?v=osLQIVR--fU.

71 First people are climbing the pole, see http://www.youtube.com/watch?v=VDOIXcobbJM, http://www.youtube.com/watch?v=MvlzywaFnmc, http://www.youtube.com/watch?v=6SXgp3VIM88.

72 The third police cordon dissolves, see http://www.youtube.com/watch?v=_PQqBePT6ig and http://www.youtube.com/watch?v=QpzlSdBE3dA.

73 Visitors are using the small staircase to get up to the festival areas, see http://www.youtube.com/watch?v=so6-7Ezeo3U.

74 Someone has climbed a traffic sign, see http://www.youtube.com/watch?v=so6-7Ezeo3U\#t=2m41s.

75 A fourth police cordon is formed in the upper area of the ramp, see $\mathrm{http}: / /$ www.youtube.com/watch?v=ignCf7-BnBg.

76 Crowd shouting 'Die Mauer muss weg!' ['We must get rid of the wall (cordon)!'], see http://www.youtube.com/watch?v=OpdOrZVsspQ

77 Jamming on the upper part of the ramp, where visitors try to enter the festival area, see http://www.youtube.com/watch?v=WcQ21EmK7u0 [Kamera 12 (14:00-14:20)] http://www.youtube.com/watch?v=ZJ28eiBoS0g [Kamera 13 (14:00-14:20)].

78 Visitors climb the slopes to reach the festival area from the ramp, see http://www.youtube.com/watch?v=5IB6N6cSVxA.

79 According to the YouTube description, a policeman says: 'The venue is full.', and people overcome fences to get to the festival area from the tunnel, see http://www.youtube.com/watch?v=kOjjW7Jp_Uw and http://www.youtube.com/watch?v=jm-ScKTV6nw.

80 Flow on staircase, see http://www.youtube.com/watch?v=VDOIXcobbJM\#t=4m50s.

81 People scream for their lives, see http://www.youtube.com/watch?v=y_agoPIP_dA\#t=4m22s.

82 A bent traffic sign can be seen here: http://www.youtube.com/watch?v=VDOIXcobbJM; later on, it disappeared below the crowd, see http://www.youtube.com/watch?v=rzz5geLWPV4.

83 People shout that others should move on more quickly, see http://www.youtube.com/watch?v=t3nDQti-zDY and http://www.youtube.com/watch?v=t3nDQti-zDY.

84 Signs of crowd turbulence around the pole, see http://www.youtube.com/watch?v=h3ik6n2BPa8 
http://www.youtube.com/watch?v=UWXXDEZ4oKg http://www.youtube.com/watch?v=YmQR6kgwSXA http://www.youtube.com/watch?v=r1toPUusRGU.

86 An unconscious woman is carried over the crowd towards the staircase, see http://www.youtube.com/watch?v=KbvDLmQTED8.

87 Slowly moving crowd in the tunnel, see http://www.youtube.com/watch?v=CPcH4zZtY7w.

88 Loud speaker announcement stating 'The venue is full.', see http://www.youtube.com/watch? $\mathrm{v}=\mathrm{Y} 85 \mathrm{n}$ UacO2GU.

89 Problems between staircase and tunnel, see http://www.youtube.com/watch?v=8aTXT3ht8VU.

90 Many people raising their hands, hoping for help (visible in full screen mode), see http://www.youtube.com/watch?v=11HLIn78650.

91 An emergency vehicle enters the ramp, see http://www.youtube.com/watch?v=XKo3rb5R_Dc.

92 http://www.youtube.com/watch?v=0VEbvBMrAG8.

93 A few people crawl on top of others, see http://www.youtube.com/watch?v=xxd_KlaCiNY.

94 Videos showing people crawling or walking on others, see http://www.youtube.com/watch?v=JPIn5DPInB4, http://www.youtube.com/watch?v=y_agoPIP_dA, and http://www.youtube.com/watch?v=OfQjXi3J3ns.

95 People climb up from the container in the South, see http://www.youtube.com/watch? $\mathrm{v}=2 \mathrm{~B} 502 \mathrm{wgdH}$ cw.

96 Loveparade 2010 Disaster FullHD.mp4 16:54 - 17:03, see http://www.youtube.com/watch?v=OfQjXi3J3ns.

97 People are pulled up from the container, see http://www.youtube.com/watch?v=loxPIvrFCNg.

98 A woman screams for her life, see http://www.youtube.com/verify_age?next_url=/watch\%3Fv\%3D3×00DBo4gb8.

99 Many people yell for help, see http://www.youtube.com/watch?v=Yx|Zwvvhpp8.

$100 \mathrm{http}: / /$ www.youtube.com/watch?v=t3_3UIZS3dw.

101 http://www.youtube.com/watch?v=Kc8wEMiOxoo.

102 http://www.youtube.com/watch?v=BbCrmUZeJoY.

$103 \mathrm{http}: / /$ www.youtube.com/watch?v=NLC3vyp0b9U.

$104 \mathrm{http}: / /$ www.youtube.com/watch?v=OgJYkNDiDCY.

$105 \mathrm{http}: / /$ www.youtube.com/watch?v=gN4NNmxtRU4.

106 http://www.youtube.com/verify_age?next_url=/watch\%3Fv\%3Ds2ywRwxfHbo.

$107 \mathrm{http}: / /$ www.youtube.com/watch?v=QCAVAYDolKc.

$108 \mathrm{http}: / /$ www.youtube.com/watch?v=JfaLr_Y4U18.

109 http://www.youtube.com/watch?v=-iCA6g984aY.

$110 \mathrm{http}: / /$ www.youtube.com/watch?v=LXLuogNDJ-A.

$111 \mathrm{http}: / /$ www.youtube.com/watch?v=FYXQLgd_VA8.

$112 \mathrm{http}: / /$ www.youtube.com/watch?v=Nb0m_nOKGms.

$113 \mathrm{http}: / /$ www.youtube.com/watch?v=-7WDbM4EonY http://www.youtube.com/watch?v=zCRGtjcbyw8 http://www.youtube.com/watch?v=gEa9_k-Th7U http://www.youtube.com/watch?v=_CiEkTPk9BQ.

114 Operation room of the city of Duisburg considers the Love Parade as success as late as 17:15, see http://www.youtube.com/watch?v=S9ILNAv0J1A and http://www.youtube.com/watch?v=FHD8aqsCr9U.

$115 \mathrm{http}: / /$ www.youtube.com/watch?v=qQbto4MNqOU.

$116 \mathrm{http}: / /$ www.youtube.com/watch?v=WR56iEfBQoo.

117 Videos of the continuation of the Love Parade after the Crowd Disaster, see http://www.youtube.com/watch?v=Dz8dID-xTBo.

118 RTL documentation, see http://www.youtube.com/watch?v=fy1NDX_nA3M.

119 Falling from staircase as assumed cause of the crowd disaster, see: http://www.n-tv.de/panorama/Loveparade-endet-im-Unglueck-18-Menschen-sterben-article1127116.html, http://www.youtube.com/watch?v=IreaH16lm_c, http://www.youtube.com/watch?v=Dz8dID-xTBo.

120 Mass panic (stampede) as assumed cause of the crowd disaster, see: http://www.focus.de/panorama/welt/loveparade-mindestens-15-tote-nach-massenpanik_aid_533916.html http://www.welt.de/die-welt/politik/article8627956/15-Tote-bei-der-Love-Parade.html http://www.videoportal.sf.tv/video?id=b5b05584-57b7-42fe-bbb3-5c28d96ff6aa.

121 Wrong behavior of people assumed as reason for the crowd disaster: http://mp3-download.swr.de/swr1/bw/leute/michael-schreckenberg-stauexperte-und-panikforscher.6444m.mp3 and http://www.youtube.com/watch?v=YCXAfXjXom4.

122 Wikipedia article on stampedes, see http://en.wikipedia.org/wiki/Stampede.

123 For information on the stampede in Baghdad on August 25. 2005, see http://en.wikipedia.org/wiki/2005_Baghdad_bridge_stampede.

124 For information on the Chicago night club disaster on February 17, 2003, see http://en.wikipedia.org/wiki/2003_E2_nightclub_stampede. 
125

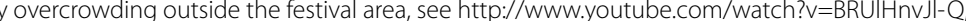
http://www.youtube.com/watch?v=OpdOrZVsspQ, http://www.youtube.com/watch?v=2aJojVYOE9A, and http://www.youtube.com/watch?v=DTbJ_vbT8Cw. See also the endnote. ${ }^{128}$

126 Surveillance videos by the organizers of the Love Parade in Duisburg, showing the situation on the upper part of the ramp:

http://www.youtube.com/watch?v=WcQ21EmK7u0 http://www.youtube.com/watch?v=9v7|PPYfBX0 http://www.youtube.com/watch?v=M8113-3E56w http://www.youtube.com/watch?v=GcqLFE_pdq0 http://www.youtube.com/watch?v=5IB6N6cSVXA http://www.youtube.com/watch?v=eYL-LTYaprO http://www.youtube.com/watch?v=SHrL205JY7M http://www.youtube.com/watch?v=krryGhZshg8.

127 Videos showing the overcrowded ramp and visitors moving up the slopes left and/or right of the ramp towards the festival area: http://www.youtube.com/watch?v=qZNrGBBw-nA http://www.youtube.com/watch?v=loX7-LviRrO http://www.youtube.com/watch?v=AN_8zwycDYO http://www.youtube.com/watch?v=fjQMaO7IBmQ, and http://www.youtube.com/watch?v=36YITJTrRAc. Accordingly to our notes, early crowd turbulence on the upper part of the ramp leading onto the festival area was visible on the video http://video.web.de/watch/7678046, when we accessed it around May 9, 2011, but it does not seem to be available in the Web anymore. According to the archive provided by the Wayback Machine at http://www.archive.org/, this video was apparently linked to an article entitled 'NRW erhebt schwere Vorwürfe gegen Veranstalter von Love Parade', which was published by web.de.

129 A float is slowly passing the ramp when people start using the slopes to get to the festival area, see http://www.youtube.com/watch?v=N1 pToqkroZE and http://www.youtube.com/watch?v=5IB6N6cSVxA [Kamera $12(15: 20-15: 40)]$.

130 'Pushers' are people, who are supposed to put pressure on visitors to keep moving, in this case to ensure an efficient entering into the festival area in order to avoid an obstruction of other visitors trying to get in.

131 First person climbs the container around 16:24, see http://www.youtube.com/watch?v=_PQqBePT6ig and http://www.youtube.com/watch?v=yjefyv8ShfY

132 People offering help (e.g. water), see http://www.youtube.com/watch?v=VDOIXcobbJM and http://www.youtube.com/watch?v=COzLKDEglOs.

133 Group pushing to the tunnel, see http://www.youtube.com/watch?v=0VEbvBMrAG8 around time 1:07.

134 'The staircase should have been blasted away', see http://www.sueddeutsche.de/wissen/loveparade-experte-zur-ungluecksursache-die-treppe-haette-mansprengen-muessen-1.979428-2; http://www.tagesanzeiger.ch/panorama/vermischtes/Die-Treppe-haette-man-sprengen-muessen/story/10003282.

135 For photographs of the accident area see http://loveparade2010doku.files.wordpress.com/2011/08/ungluecksstelle-loveparade6.jpg, http://hvg.hu/nagyitas/20100726_love_parade_duisburg_nagyitas\#kep8, http://farm5.static.flickr.com/4134/4912001905_3871745170_o.jpg. For further photographs of the Love Parade disaster, see http://loveparade2010doku.wordpress.com/bilder/ and http://www.wz-newsline.de/home/panorama/die-tragoedie-auf-der-loveparade-2010-1.21599.

136 Someone falling down, when trying to climb the staircase from the side, see http://www.youtube.com/watch?v=JiglrMkWdYY, http://www.youtube.com/user/rkjorge70, and http://www.youtube.com/user/LoveparadeDuisburg?feature=watch.

137 'Let us take the staircase' ('Wir nehmen die Treppe'), see http://loveparade2010doku.wordpress.com/2010/07/28/loveparade-2010-zeitablauf-sperrungen-unddurchlassungen/.

138 The flow of people on the staircase is considerably obstructed by people, who climb the staircase from the side, see http://www.youtube.com/watch?v=G-mfsxz2k2g.

139 Falling due to the turbulent waves in the crowd, see http://www.youtube.com/watch?v=S9ILNAv0J1A.

140 Domino effect in the crowd and involuntary stepping on others to survive, see http://www.wdr.de/mediathek/html/regional/2011/07/19/lokalzeit-duisburg-loveparade.xml.

141 Crowd turbulence as assumed cause of the crowd disaster, see http://www.pressetext.com/news/20100729019.

142 Eyewitnesses describing the cause of the disaster, see http://www.youtube.com/watch?v=b79riRVinJs and http://www.youtube.com/watch?v=S9ILNAvOJ1A.

143 For signs of crowd turbulence on lower part of the ramp see http://www.youtube.com/watch?v=QpzISdBE3dA [Kamera 13: 16:20-16:40], http://www.youtube.com/watch?v=JiglrMkWdYY, and http://www.youtube.com/watch?v=-2onoJLq2-8. It seems, however, that crowd turbulence occurred even earlier in the upper part of the ramp; a video showing this with the file name http://video.web.de/watch/7678046 was apparently linked to the following web.de article: NRW erhebt schwere Vorwürfe gegen Veranstalter von Love Parade Video, but it is not accessible anymore.

144 Note that the fallen people in the video recording are in the shadow. Therefore, one must use full screen mode to notice them, and one needs to watch out for arms raised in the air, seeking for help. 
145 Videos of the area where the victims were located, see http://www.youtube.com/watch? v=WR56iEfBQoo, http://www.youtube.com/watch?v=qbQr5yAjqxs, and http://www.youtube.com/watch?v=FYXQLgd_VA8, http://www.youtube.com/watch?v=JPIn5DPInB4, and endnotes. ${ }^{47,48}$

146 http://loveparade2010doku.wordpress.com/2010/07/28/loveparade-2010-zeitablauf-sperrungen-unddurchlassungen/ (nach 16:57, 'Einschub')

147 Pictures of the broken manhole, see http://www.dailymotion.com/video/xfl3rc_rtl2-100tage-loveparade-ausschnitte_news.

148 Moreover, video recordings of the situation around the emergency vehicle do not show clear evidence of turbulent motion in its immediate neighborhood.

149 Video recordings of the situation around the emergency vehicle on the ramp, see http://www.youtube.com/watch?v=0VEbvBMrAG8, http://www.youtube.com/watch?v=yNuh9Hk_tgM http://www.youtube.com/watch?v=Z5mf7imNrlY, http://www.youtube.com/watch?v=G-mfsxz2k2g, http://www.youtube.com/watch?v=dP-5VOCU30U, and http://www.youtube.com/watch?v=rzz5geLWPV4.

150 For some aerial photographs of the festival area of the Love Parade in Berlin see http://www.skyscrapercity.com/showpost.php?s=e6cd40536463e09d85e914ba4372578f\&p=60946437\& postcount $=44$.

151 Private communication; for further eye witness reports see http://loveparade2010doku.wordpress.com/2010/07/27/erinnerungen-von-augenzeugen-zusammengefasst-undverlinkt/.

152 Eye witness report, Anlage 68 [attachment no. 68] at https://www.duisburg.de/ratsinformationssystem/bi/vo0050.php?_kvonr=20056110\&voselect=20049862.

153 Surveillance by police and helicopter, see http://www.youtube.com/watch?v=t3_3UIZS3dw, http://www.youtube.com/watch?v=8aQuTaMbS38, http://www.youtube.com/watch?v=YmQR6kgwSxA and endnote ${ }^{93}$.

154 Situation after 17:20 on the main ramp, entering of a loudspeaker vehicle, and activities in the tunnel, see http://www.youtube.com/watch?v=XgCByAtNXmY, http://www.youtube.com/watch?v=SqqdnzAsF60 (removed) http://www.youtube.com/watch?v=ffqkFOXX3AM, http://www.youtube.com/watch?v=y4W3xb-SMDs, and http://www.youtube.com/watch?v=j11330qbfb4.

155 The police attempts to direct the crowd on the ramp to the upper end, see http://www.youtube.com/watch?v=3XFTVWUN8nw.

156 This was previously prevented by fences.

157 The seriousness of the situation is not recognized, despite the extremely crowded situation around the pole, the container, and the staircase, see http://www.youtube.com/watch?v=9E32qAeOBOk, http://www.youtube.com/watch?v=-2onoJLq2-8, http://www.youtube.com/watch?v=fL_1reQrERg, http://www.youtube.com/watch?v=N795HhESDkw and http://www.youtube.com/watch?v=OfQjXi3J3ns; also note that most videos do not record the accident area for a long time-the filmers do not seem to notice the location where the conditions was most critical.

158 Many visitors follow the leaving emergency vehicle up the ramp, see http://www.youtube.com/watch?v=rzz5geLWPV4 and http://www.youtube.com/watch?v=dP-5VOCU30U.

159 O. Ackermann et al., Patient care at the 2010 Love Parade in Duisburg, Germany: Clinical experiences, Deutsches Ärzteblatt International 108(28/29), 483-489 (2011), see http://www.ncbi.nlm.nih.gov/pmc/articles/PMC3149288/; see also http://www.youtube.com/watch?v=S9ILNAv0J1A.

160 Or even several interrelated systemic instabilities (since the phenomenon of 'crowd turbulence' itself can be seen as outcome of an instability of visitor flows).

161 D. Helbing (2010) Systemic Risks in Society and Economics. International Risk Governance Council (irgc), see http://www.irgc.org/IMG/pdf/Systemic_Risks_Helbing2.pdf.

162 In a letter dated July 22, 2009, from the (British) Royal Academy to Her Majesty, the Queen, the following explanation was given for the financial crisis, see http://www.euroresidentes.com/empresa_empresas/carta-reina.pdf: '... where was the problem? Everyone seemed to be doing their own job properly on its own merit. And according to standard measures of success, they were often doing it well. The failure was to see how collectively this added up to a series of interconnected imbalances over which no single authority had jurisdiction.... Individual risks may rightly have been viewed as small, but the risk to the system as a whole was vast.' This quote illustrates the mechanism of systemic instability quite well (which may be defined as a situation in which things can get totally out of control, even when everyone is trying to do his or her job in an adequate way).

163 http://www.metropoleruhr.de/en/home/ruhr-metropolis/data-facts.html.

164 Some tolerable risks associated with the normal entering and leaving of the area are mentioned, but have not been investigated in detail by computer simulations.

165 Jamming due to the later start of the Love Parade and criticism of the lack of flow separation, see http://www.wdr.de/mediathek/html/regional/2010/07/26/lokalzeit-duisburg-loveparade-floatveranstalter.xml.

166 The emergency forces were not prepared for the large number of injuries, see http://www.youtube.com/watch?v=DTbJ_vbT8Cw.

167 Police supports people moving up the narrow staircase from 16:35, see http://www.youtube.com/watch?v=AYjlXhPcF4s.

168 A. Johansson, Data-Driven Modeling of Pedestrian Crowds (VDM Publishers Dr. Mueller, 2009), see http://tud.qucosa.de/fileadmin/data/qucosa/documents/2090/dissertation_johansson_tudresden.pdf and also http://www.crowdvision.co.uk. 
169 Comparison of the flow organization of the Love Parade (characterized by counterflows) with an alternative, circular flow concept, see http://loveparade2010doku.wordpress.com/2010/07/28/das-umgesetzte-wegekonzept-der-loveparade-2010und-eine-von-vielen-moglichen-alternativen-im-vergleich/.

170 People do not seem to panic easily, but panic mainly appears to occur when people are suddenly shocked (e.g. by a gun shot) or the danger is imminent. If there is time to think, panic is less likely. For example, when the 'Titanic' sank slowly, evacuation attempts were largely controlled by social norms, while selfish rescue attempts dominated, when the 'Lusitania' sank quickly, see B.S. Frey, D.A. Savage, and B. Torgler, Interaction of natural survival instincts and internalized social norms exploring the Titanic and Lusitania disasters, PNAS 107, 4862-4865 (2010).

171 An example for a crowd crush is the crowd disaster in Minsk, Belarus, on May 30, 1999, where a sudden thunderstorm with heavy rain caused people to stream into the near-by 'Nyamiha' metro station, see http://www.charonboat.com/item/79 and http://en.wikipedia.org/wiki/Minsk_Metro

172 An example of crowd panic is the Baghdad bridge stampede on August 31, 2005, where pilgrims moving toward the Al Kadhimiya Mosque got nervous due to rumors of an imminent suicide bomb attack, after there had been already armed conflict on the same day, see http://en.wikipedia.org/wiki/2005_Baghdad_bridge_stampede.

173 Such turbulent waves are also often observed during rock concerts, when the crowd is very dense.

174 Mitarbeiter der Stadt Duisburg werden angefeindet [Staff of the City of Duisburg publicly attacked], see http://www.derwesten.de/staedte/duisburg/mitarbeiter-der-stadt-duisburg-werden-angefeindet-id3319267.html.

\section{Received: 9 May 2012 Accepted: 25 May 2012 Published: 25 June 2012}

\section{References}

1. The Scottish Office (1997) Guide to safety at sports grounds, 4th edn. The Stationery Office, Norwich

2. Health and Safety Executive (1999) The event safety guide. HSE Books, Norwich

3. Health and Safety Executive (2000) Managing crowds safely. HSE Books, Norwich

4. Health and Safety Executive (1998) Steps to risk assessment. Case studies. HSE Books, Norwich

5. Independent Street Arts Network (2004) Safety guidance for street arts, carnival, processions, and large-scale performances. Independent Street Arts Network, London

6. Predtechenskii VM, Milinskii Al (1978) Planning for foot traffic flow in buildings. Amerind, New Delhi

7. Fruin JJ (1993) The causes and prevention of crowd disasters. In: Smith RA, Dickie JF (eds) Engineering for crowd safety. Elsevier, Amsterdam, pp 99-108

8. Schreckenberg M, Sharma SD (eds) (2002) Pedestrian and evacuation dynamics. Springer-Verlag, Heidelberg. See in particular the chapter by D. Helbing, I. Farkas, P. Molnár, and T. Vicsek, Simulation of pedestrian crowds in normal and evacuation situations, pp 21-58

9. Helbing D, Buzna L, Johansson A, Werner T (2005) Self-organized pedestrian crowd dynamics: experiments, simulations, and design solutions. Transp Sci 39(1):1-24

10. Schadschneider A, Klingsch W, Klüpfel H, Kretz T, Rogsch C, Seyfried A (2009) Evacuation dynamics: empirical results, modeling and applications. In: Encyclopedia of complexity and systems science 3. Springer, Berlin, pp $3142 \mathrm{ff}$

11. Helbing D, Johansson A (2010) Pedestrian, crowd and evacuation dynamics. Encyclopedia of Complexity and Systems Science 16:6476-6495

12. Johansson A, Helbing D, A-Abideen HZ, Al-Bosta S (2008) From crowd dynamics to crowd safety: a video-based analysis. Adv Complex Syst 11(4):497-527. See also http://www.trafficforum.org/crowdturbulence

13. Haase K (2006) Scheduling of Hajjis Groups in Hajj 1427H. Specialized Architectural, Engineering \& Technical Reviewed Magazine issued by Ministry of Municipal \& Rural Affairs 10:70-75, Saudi Arabia

14. Haase K (2007) Scheduling and re-scheduling the departure and stoning times of the Hajjis in $1428 \mathrm{H}$. Specialized Architectural, Engineering \& Technical Reviewed Magazine issued by Ministry of Municipal \& Rural Affairs, Saudi Arabia

15. Serwill D, Vollmer R, Al Bosta S, Tayara A (10/2009) Design and organization of the Jamarat stoning process at Hajj 1427-1430H, IVV (Ingenieurgruppe IVV), Aachen-Riyadh

16. Al Nabulsi HH (2009) How can vulnerability and risk be reduced in large-scale gatherings? An assessment of vulnerability and risk in mass gatherings. MA thesis, School of Built Environment, Oxford Brookes University, Oxford

17. Helbing D, Isobe M, Nagatani T, Takimoto K (2003) Lattice gas simulation of experimentally studied evacuation dynamics. Phys Rev E, Stat Nonlinear Soft Matter Phys 67:067101

18. Isobe M, Helbing D, Nagatani T (2004) Experiment, theory, and simulation of the evacuation of a room without visibility. Phys Rev E, Stat Nonlinear Soft Matter Phys 69:066132

19. Kirchner A et al (2003) Simulation of competitive egress behavior: comparison with aircraft evacuation data. Physica A 324:689-697

20. Hoogendoorn SP, Daamen W (2005) Pedestrian behavior at bottlenecks. Transp Sci 39(2):147-159

21. Nilsson D, Johansson A (2009) Social influence during the initial phase of a fire evacuation-Analysis of evacuation experiments in a cinema theatre. Fire Saf J 44(1):71-79

22. Seyfried A et al (2009) New insights into pedestrian flow through bottlenecks. Transp Sci 43(3):395-406

23. Klingsch W, Rogsch C, Schadschneider A, Schreckenberg M (eds) (2010) Pedestrian and evacuation dynamics 2008. Springer, Berlin

24. Fang Z, Song W, Zhang J, Wu H (2010) Experiment and modeling of exit-selecting behaviors during a building evacuation. Physica A 389:815-824

25. Daamen W, Hoogendoorn SP (2012) Emergency door capacity: influence of door width, population composition and stress level. Fire Technol 48(1):55-71

26. Helbing D (1991) A mathematical model for the behavior of pedestrians. Behav Sci 36:298-310

27. Moussaïd M, Helbing D, Theraulaz G (2011) How simple rules determine pedestrian behavior and crowd disasters. Proc Natl Acad Sci USA 108(17):6884-6888 
28. Helbing D, Molnár P (1995) Social force model for pedestrian dynamics. Phys Rev E, Stat Nonlinear Soft Matter Phys 51:4282-4286

29. Helbing D, Farkas I, Vicsek T (2000) Simulating dynamical features of escape panic. Nature 407:487-490

30. Burstedde C, Klauck K, Schadschneider A, Zittartz J (2001) Simulation of pedestrian dynamics using a two-dimensional cellular automaton. Physica A 295(4):507-525

31. Nagatani T (2002) The physics of traffic jams. Rep Prog Phys 65:1331-1385

32. Kirchner A, Schadschneider A (2002) Simulation of evacuation processes using a bionics-inspired cellular automaton model for pedestrian dynamics. Physica A 312:260-276

33. Hoogendoorn S (2004) Pedestrian flow modeling by adaptive control. Transp Res Rec 1878:95-103

34. Helbing D, Johansson A, Mathiesen J, Jensen MH, Hansen A (2006) Analytical approach to continuous and intermittent bottleneck flows. Phys Rev Lett 97:168001

35. Antonini G, Bierlaire M, Weber M (2006) Discrete choice models of pedestrian walking behavior. Transp Res, Part B, Methodol 40(8):667-687

36. Yu W, Johansson A (2007) Modeling crowd turbulence by many-particle simulations. Phys Rev E 76:046105

37. Moussaïd M et al (2009) Experimental study of the behavioural mechanisms underlying self-organization in human crowds. Proc R Soc B 276:2755-2762

38. Weidmann U (1993) Transporttechnik der Fußgänger. Schriftenreihe des Institut für Verkehrsplanung, Transporttechnik, Straßen- und Eisenbahnbau 90, ETH Zürich, Zürich

39. Transportation Research Board (1985) Highway capacity manual. Special Report 209. Transportation Research Board, Washington DC. See the chapter on pedestrians

40. Polus A, Schofer JL, Ushpiz A (1983) Pedestrian flow and level of service. J Transp Eng 109:46-56

41. Fruin JJ (1971) Designing for pedestrians: a level-of-service concept. Highw Res Rec 355:1-15

42. Moussaïd M, Perozo N, Garnier S, Helbing D, Theraulaz G (2010) The walking behaviour of pedestrian social groups and its impact on crowd dynamics. PLOS ONE 5(4):e10047

43. Helbing D (2001) Traffic and related self-driven many-particle systems. Rev Mod Phys 73:1067-1141

44. MacKay C (2003) Extraordinary popular delusions and the madness of crowds. Harriman House, Petersfield, Hampshire

45. Keating JP (1982) The myth of panic. Fire J 76:57-61, 147

46. Helsloot I, Ruitenberg A (2004) Citizen response to disasters: a survey of literature and some practical implications. J Conting Crisis Manag 12(3):98-111

47. Helbing D (1992) Models for pedestrian behavior. In: Natural structures. Principles, strategies, and models in architecture and nature, part II. Sonderforschungsbereich 230, Stuttgart, pp 93-98. See also Ref. [9] and D. Helbing, Verkehrsdynamik (Springer, Berlin, 1997)

48. Helbing D, Johansson A, Al-Abideen HZ (2007) The dynamics of crowd disasters: an empirical study. Phys Rev E, Stat Nonlinear Soft Matter Phys 75:046109

49. Helbing D, Farkas I, Vicsek T (2000) Freezing by heating in a driven mesoscopic system. Phys Rev Lett 84:1240-1243

50. Helbing D, Kühnert C (2003) Assessing interaction networks with applications to catastrophe dynamics and disaster management. Physica A 328:584-606

51. Sugiyama Y et al (2008) Traffic jams without bottlenecks - experimental evidence for the physical mechanism of the formation of a jam. New J Phys 10:033001

52. Hardin G (1968) The tragedy of the commons. Science 162:1243-1248

53. Helbing D, Johansson A (2010) Cooperation, norms, and revolutions: a unified game-theoretical approach. PLoS ONE 5(10):e12530

54. Helbing D, Johansson A (2010) Evolutionary dynamics of populations with conflicting interactions: classification and analytical treatment considering asymmetry and power. Phys Rev E, Stat Nonlinear Soft Matter Phys 81:016112

55. Helbing D FuturICT - New science and technology to manage our complex, strongly connected world. Preprint. http://arxiv.org/abs/1108.6131

56. Helbing D, Ammoser H, Kühnert C (2005) Disasters as extreme events and the importance of network interactions for disaster response management. In: Albeverio S, Jentsch V, Kantz $\mathrm{H}$ (eds) Extreme events in nature and society. Springer, Berlin, pp 319-348

57. Peters K, Buzna L, Helbing D (2008) Modelling of cascading effects and efficient response to disaster spreading in complex networks. Int J Crit Infrastructures 4(1/2):46-62

58. Simonsen I, Buzna L, Peters K, Bornholdt S, Helbing D (2008) Transient dynamics increasing network vulnerability to cascading failures. Phys Rev Lett 100:218701

59. Buzna L, Peters K, Ammoser H, Kühnert C, Helbing D (2007) Efficient response to cascading disaster spreading. Phys Rev E, Stat Nonlinear Soft Matter Phys 75:056107

60. Helbing D (2012) Accelerating scientific discovery by formulating grand scientific challenges. EPJ Special Topics (to appear)

doi:10.1140/epjds7

Cite this article as: Helbing and Mukerji: Crowd disasters as systemic failures: analysis of the Love Parade disaster. EPJ Data Science 2012 1:7 